\title{
Proposta de método de projeto baseado no desempenho para edifícios energeticamente eficientes
}

\author{
Performance-based design method for energy efficient \\ buildings
}

\section{Lucas Martinez da Costa \\ Cristina Engel de Alvarez Jarryer Andrade de Martino}

\section{Resumo}

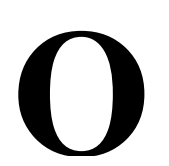

desenvolvimento da tecnologia digital nas últimas décadas possibilitou o surgimento de novos métodos e técnicas para a elaboração de projetos com ênfase na busca da eficiência energética. $\mathrm{O}$ intuito deste trabalho foi propor um método de projeto baseado no desempenho com o objetivo de associar a modelagem paramétrica, otimização baseada em simulação, avaliação e classificação da eficiência energética para edifícios de escritório. Para isso foram utilizados os programas Rhinoceros/Grasshopper, Opossum e Honeybee, respectivamente. Os modelos de projetos digitais elaborados por Oxman (2006) foram empregados como referência para estruturar os experimentos dos estudos de caso representados em edifícios localizados em Vitória, ES. Os parâmetros da Instrução Normativa INMETRO para a Classe de Eficiência Energética de Edificações Comerciais, de Serviço e Públicas (INI-C) balizaram as avaliações. Como resultado do método, obteve-se uma melhoria de $31 \%$ no consumo total de energia primária e uma redução de $54 \%$ na demanda por refrigeração nos edifícios. A estimativa de influência demonstrou os impactos significativos na alteração do tipo de vidro, no percentual de abertura da fachada e na configuração dos sombreadores. Apesar das particularidades, verificou-se o potencial de aplicação do método no estágio inicial de desenvolvimento de projetos.

Palavras-chave: Metodologia de projeto. Projeto baseado no desempenho. Desempenho energético nas edificações. Edifícios de escritórios.

${ }^{1}$ Lucas Martinez da Costa ${ }^{1}$ Universidade Federal do Espírito Santo Vitória - ES - Brasil

${ }^{2}$ Cristina Engel de Alvarez ${ }^{2}$ Universidade Federal do Espírito Santo Vitória - ES - Brasil

3 Jarryer Andrade de Martino ${ }^{3}$ Universidade Federal do Espírito Santo Vitória - ES - Brasil

Recebido em 29/03/20

Aceito em 28/06/20

\section{Abstract}

Progress in digital technology over the past decades has enabled the emergence of new methods and techniques for design development with an emphasis on energy efficiency. The aim of this paper was to propose a performative design method for office buildings associating parametric modelling, optimisation-based simulation, evaluation and classification of energy performance. In order to do that, the Rhinoceros/Grashopper,

Opossum and Honeybee softwares were used, respectively. The digital design models by Oxman (2006) were used as reference to structure experiments from case studies of office buildings located in Vitória, ES, Brazil. The parameters of the INMETRO standard for Energy Efficiency Class for Commercial, Service and Public Buildings (INI-C) guided the evaluations. The method resulted in a $31 \%$ improvement in the total consumption of primary energy and a 54\% reduction in the demand for refrigeration in buildings. The estimate of the influence demonstrated significant impacts from the alteration of the type of glass, percentage of façade opening and the configuration of shaders. The study showed that, despite the particularities, there is potential for applying the method in the initial stages of design development.

Keywords: Design Method. Performative design. Energy performance in buildings. Office buildings.

COSTA, L. M. da; ALVAREZ, C. E. de; MARTINO, J. A. de. Proposta de método de projeto baseado no desempenho 409 para edifícios energeticamente eficientes. Ambiente Construído, Porto Alegre, v. 21, n. 2, p. 409-433, abr./jun. 2021. ISSN 1678-8621 Associação Nacional de Tecnologia do Ambiente Construído. http://dx.doi.org/10.1590/s1678-86212021000200533 


\section{Introdução}

O setor da construção civil tem ocasionado, nas últimas décadas, amplos impactos com relação ao consumo de energia elétrica em âmbito mundial, com uma representatividade de $31 \%$ dos gastos em relação às demais atividades produtivas, associado à expectativa de crescimento de $0,9 \%$ ao ano até 2040 (INTERNATIONAL..., 2019). Diante desse cenário, é inquestionável a urgência de novas abordagens relativas a métodos e técnicas para a elaboração de projetos, com ênfase na eficiência energética (NEGENDAHL, 2015). Contudo, apesar dos avanços significativos da tecnologia digital, a utilização de ferramentas computacionais que permitam a aplicação de procedimentos de parametrização, simulação e otimização como aporte na concepção de edifícios de alto desempenho energético ainda passa por um longo processo de inserção na realidade profissional, tanto dos arquitetos como dos engenheiros.

Diante desse cenário, uma das principais potencialidades que impulsionam a penetração da computação no cerne da prática projetual diz respeito à estruturação e à mediação das informações (TERZIDIS, 2006). Pode-se afirmar que, diferente da prática convencional, o projeto digital estabelece uma conexão singular entre o projetista, as ferramentas computacionais e os atributos das edificações, a fim de auxiliar no processo de resolução de problemas (OXMAN, 2006). De acordo com a mesma autora, essa nova interação pode ser realizada pela relação entre os elementos que compõem a sequência de decisões durante as etapas de projeto, dos quais se destacam:

(a) a representação, relacionada à interface gráfica;

(b) a geração, caracterizada por processos de estruturação e de interação da forma;

(c) a avaliação, que destaca os procedimentos análise/julgamento; e

(d) a otimização/desempenho, que incluem considerações programáticas e contextuais.

Além disso, destaca-se o modo como se define o fluxo de informações, que pode ocorrer de forma implícita, baseado em informações não formalizadas como em atividades manuais, ou explícita, nos casos em que o projetista interage com um conjunto de regras e relações estabelecidas em uma estrutura digital (ANDRADE; RUSCHEL, 2012).

Na modelagem paramétrica, por exemplo, suas características conceituais - como a geometria associativa ${ }^{1}$, os esquemas topológicos ${ }^{2}$ relacionais e a reedição de processos $^{3}$ - auxiliam na correlação de parâmetros de elementos arquitetônicos, que frequentemente ocorrem de forma explícita (JABI, 2013; WOODBURY, 2010). Essa capacidade contribui para o desenvolvimento dos sistemas generativos de projeto, os quais se definem pelo código de programação da modelagem, com a intermediação e encadeamento lógico das variáveis para a geração de soluções na concepção dos edifícios (MONIZZA; BENDETTI; MATT, 2018). A técnica também auxilia na composição de elementos, assim como na formação de relações que afetam diretamente a eficiência energética da edificação, principalmente quando se refere à etapa inicial de projeto.

Outra abordagem presente no meio científico diz respeito aos algoritmos de otimização baseados em simulação e sua aplicabilidade em pesquisas que se pautam no desempenho energético. Como objetivo, o processo de otimização visa alcançar um resultado ótimo (ou mais próximo do ideal) para uma determinada condição de desempenho tendo em vista as variáveis delimitadas pelo projetista. Para que isso ocorra é necessário que o projeto seja submetido a métodos de iteração automatizada, por meio de técnicas matemáticas ou estatísticas (EVINS, 2013; MACHAIRAS; TSANGRASSOULIS; AXARLI, 2014; ØSTERGÅRD; JENSEN; MAAGAARD, 2016). Observa-se que muitas dessas ferramentas possuem interoperabilidade com softwares de modelagem paramétrica, o que intensifica a capacidade de exploração de opções de projeto para uma mesma problemática.

Tendo em vista esses fatores, bem como a necessidade de abordagens que favoreçam o desempenho energético, vale ressaltar que é indispensável a utilização de regulamentos ou instrumentos que possam normatizar a avaliação e a classificação do nível de desempenho energético das edificações na etapa de projeto (WONG; KRÜGER, 2017). No Brasil, somente a partir de 2001 com a chamada "Crise do Apagão" - que, inclusive, ocasionou a interrupção no fornecimento de energia elétrica - é que se observaram alguns

${ }^{1}$ Geometria na qual os elementos estão reciprocamente interconectados.

${ }^{2}$ Representam a capacidade de explorar propriedades geométricas que não variam quando as figuras são deformadas, organizando a relação entre formas, estrutura, escala e padrões.

${ }^{3}$ Diz respeito à modificação de regras em resposta à mudança de elementos programáticos.

410 Costa, L. M. da; Alvarez, C. E. de; Martino, J. A. de 
avanços quanto às políticas de eficiência energética. Dentre outras iniciativas surgidas, destaca-se, em 2003, o lançamento do programa denominado PROCEL Edifica pelo governo brasileiro por meio do Plano de Ação para Eficiência Energética em Edifícios, visando reduzir o consumo de eletricidade no setor da construção civil (BRASIL, 2001). Após alguns anos em desenvolvimento foram lançados regulamentos com a função não só de avaliar, mas, também, de certificar os projetos, como o Regulamento Técnico da Qualidade para o Nível de Eficiência Energética de Edificações Comerciais, de Serviços e Públicas (RTQ-C) e seus documentos complementares (INSTITUTO..., 2013). Como processo de melhoria na estrutura da regulamentação, houve uma revisão e consulta pública da nova formatação, passando a ser tratada como instrução normativa (BRASIL, 2018). Apesar de ser mais recente, ainda não está vigente até o momento de elaboração deste artigo. Embora se tenha tido progressos e a INI-C seja um instrumento fundamental para a política nacional em relação à eficiência energética, a situação da construção civil no Brasil ainda é preocupante, sendo que os edifícios são responsáveis por cerca de $42 \%$ do consumo de energia elétrica no país (MINISTÉRIO...; EMPRESA..., 2019). O setor de comércio e serviços, por exemplo, tem passado por uma evolução histórica (2005 a 2018) com um aumento de cerca de 3\% na demanda por eletricidade (INTERNATIONAL..., 2020)

Nessa perspectiva, a associação da potencialidade das ferramentas digitais juntamente com as exigências de desempenho energético no setor de construções tem impelido uma busca por novos processos de criação e elaboração de edifícios, a exemplo de estudos desenvolvidos por Ekici et al. (2019), Konis, Gamas e Kensek (2016) e Negendahl (2015). Apesar de algumas limitações observadas por Tian et al. (2018), como longo tempo de processamento e carência de métodos padronizados, o projeto baseado no desempenho, ou seja, aquele que explora os processos de projeto digitais de modo dinâmico com base em critérios bem definidos (KOLAREVIC, 2005), insere-se nesse âmbito como um possível caminho na mudança da prática projetual. Ele é composto de três principais formulações nas quais se fundamenta:

(a) modelo geométrico, que se relaciona com a transformação, geração e parametrização das formas;

(b) processos avaliativos, nos quais se integram a geometria e as técnicas de otimização baseadas em simulação de desempenho que transformam o modelo; e

(c) interatividade do projetista, que exerce o papel de mediador dos processos (OXMAN, 2008).

Portanto, para estabelecer soluções viáveis para problemas cada vez mais complexos como a eficiência energética dos edifícios, são necessárias metodologias de projeto que sejam capazes de conduzir o processo criativo a um resultado por meio da racionalização das atividades criativas (KOWALTOWSKI et al., 2006). Uma das estratégias para tanto é a associação dos conceitos do projeto baseado no desempenho a otimização e a parametrização (FONSECA et al., 2017). Diante desse contexto, o objetivo desta pesquisa foi propor um método de projeto baseado no desempenho capaz de associar modelagem paramétrica, otimização baseada em simulação, avaliação e classificação da eficiência energética para edifícios de escritórios.

\section{Método}

Nesta pesquisa foi estruturada uma série de processos para a proposição de um método de projeto baseado no desempenho tendo em vista a sua aplicação na fase inicial do projeto arquitetônico, uma vez que nesta etapa está concentrado um importante conjunto de decisões que impactam diretamente a eficiência energética da edificação. Para a configuração das sequências de decisões do projetista (geração, representação, otimização/desempenho e avaliação), foram adotados como referência os modelos de projetos digitais elaborados por Oxman (2006), que abrangem desde procedimentos predominantemente analógicos a interações totalmente automatizadas com auxílio de ferramentas computacionais.

Levando-se em consideração os três principais elementos do projeto baseado no desempenho caracterizados na literatura como o modelo geométrico, os processos avaliativos e a interatividade do projetista (ANDRADE, 2012; KALAY, 1999; KOLAREVIC, 2005; OXMAN, 2008, 2009), o método proposto apresenta uma configuração geral baseada em dois processos, o criativo e o sistemático. No primeiro, assim como é de praxe na prática projetual, há maior uso do sistema cognitivo com autonomia quanto à criação do conceito e partido da edificação associado à compreensão dos aspectos climáticos, programa de necessidades, bem como índices e restrições municipais. Sendo assim, a atividade inicial pode ocorrer de forma analógica, com a realização de croquis e maquetes, por exemplo. Em um segundo momento, o processo de criação se concentra na adaptação das concepções preliminares para estabelecer o sistema generativo de projeto, interpretando-o em códigos por meio das ferramentas digitais de modelagem paramétrica a fim de elaborar geometrias associativas e esquemas topológicos relacionais. Destaca-se que 
essa estratégia auxilia na interação entre os elementos arquitetônicos definidos como variáveis no procedimento de otimização baseada em simulação e por consequência permite a automatização na geração de soluções de projeto.

No processo sistemático, são elencados o algoritmo e as principais configurações da otimização, em suas fases de pré-processamento, execução e pós-processamento, conforme Nguyen, Reiter e Rigo (2014). Seguese, portanto, em loop, uma série de combinações até que se alcancem os requisitos de desempenho ou o critério de estagnação da otimização definido pelo projetista. Com a solução obtida, realiza-se o pósprocessamento dos dados (compilação das informações em gráficos, tabelas, quadros e figuras), assim como o desenvolvimento do modelo de referência para a avaliação e classificação do desempenho energético do edifício conforme a norma ou regulamento utilizado. Por fim, se o nível de eficiência requerido for atendido, prossegue-se com as etapas subsequentes de projeto, caso contrário retornam as configurações iniciais e repete-se o loop. A Figura 1 demonstra de forma esquemática a estruturação da lógica do método de projeto baseado no desempenho proposto.

A fim de que as informações se tornem mais concisas, foram elaboradas diretrizes pertinentes a cada fase de projeto com o intuito de nortear a sua correta aplicação. Vale ressaltar que não foram delimitados critérios fechados para o processo inicial de criação da geometria, considerando a liberdade e a particularidade de cada projeto. Entretanto, ainda que a modelagem paramétrica pressuponha a participação no processo criativo, a sua configuração no meio digital permite uma abordagem mais direcionada, de modo que se obtenham resultados mais satisfatórios. Sendo assim, as diretrizes foram organizadas no Quadro 1.

Para que a abordagem desenvolvida possa ser compreendida adequadamente, foi necessário estabelecer uma visão global dos processos, com a relação entre as sequências de decisão e as etapas de projeto (Figura 2). Apesar da necessidade de uma abstração pertinente aos elementos de programação para a elaboração da modelagem, o método propõe um pensamento sistêmico e cíclico, diferenciado do processo tradicional de concepção por tentativa e erro, mas sim por procedimentos sólidos, com fundamento técnico e matemático que auxiliem de modo mais objetivo a obtenção de edifícios com um alto desempenho energético. Como ressalvas, é importante enfatizar que o desenvolvimento do método de projeto baseado no desempenho pode apresentar diferenças na eficiência de sua aplicabilidade devido a três fatores principais:

(a) familiaridade do projetista com linguagens de programação para a modelagem paramétrica;

(b) tipo de algoritmo e número de variáveis utilizadas no processo de otimização; e

(c) configuração do sistema computacional utilizado para o desenvolvimento do projeto.

Embora esses fatores possam afetar a realização das tarefas, não se apresentam como limitantes, uma vez que são passíveis de melhorias e (ou) adaptações.

Figura 1 - Fluxograma geral do método de projeto proposto

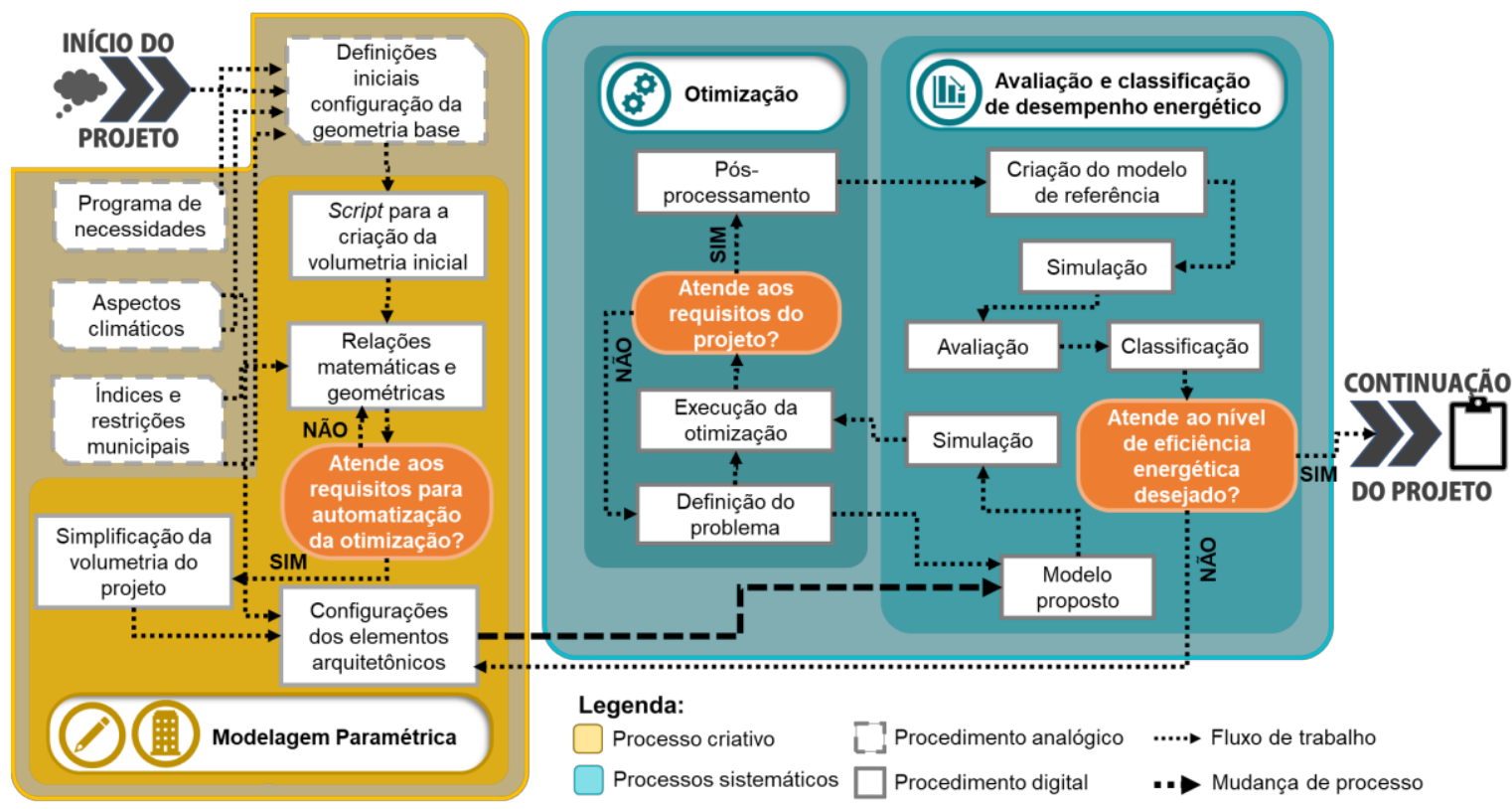

412 Costa, L. M. da; Alvarez, C. E. de; Martino, J. A. de 


\section{Quadro 1 - Diretrizes propostas para a metodologia}

\begin{tabular}{|c|c|}
\hline \multirow{6}{*}{$\begin{array}{l}\text { Modelagem } \\
\text { paramétrica }\end{array}$} & $\begin{array}{l}\text { 1. Estabelecer relações condicionais entre parâmetros e variáveis para a criação de uma } \\
\text { geometria associativa. }\end{array}$ \\
\hline & $\begin{array}{l}\text { 2. Utilizar componentes que flexibilizam a variação dos dados de entrada para a } \\
\text { automatização dos processos. }\end{array}$ \\
\hline & $\begin{array}{l}\text { 3. Evitar longos blocos de programação, pois podem exigir maior processamento do } \\
\text { computador. }\end{array}$ \\
\hline & 4. Organizar o código em grupos para facilitar a compreensão. \\
\hline & $\begin{array}{l}\text { 5. Colocar breves explicações em cada grupo como descrição do procedimento criado a } \\
\text { fim de facilitar o entendimento de códigos longos e complexos. }\end{array}$ \\
\hline & $\begin{array}{l}\text { 6. Simplificar, sempre que possível, a geometria do edifício proposto, principalmente } \\
\text { em casos que contam com um elevado número de pavimentos. }\end{array}$ \\
\hline \multirow{6}{*}{ Otimização } & $\begin{array}{l}\text { 1. Definir de forma clara a quantidade de parâmetros em cada variável a fim de não } \\
\text { despender tempo desnecessário no processo de otimização. }\end{array}$ \\
\hline & 2. Utilizar preponderantemente as variáveis que mais impactam o problema de projeto. \\
\hline & $\begin{array}{l}\text { 3. Evitar o uso de variáveis contínuas, pois prolongam o tempo de otimização devido à } \\
\text { presença de números decimais. }\end{array}$ \\
\hline & $\begin{array}{l}\text { 4. Utilizar algoritmos que atendam de maneira adequada as especificidades do objetivo } \\
\text { da otimização. }\end{array}$ \\
\hline & 5. Organizar e gravar os dados gerados em cada otimização. \\
\hline & $\begin{array}{l}\text { 6. Proporcionar, sempre que possível, uma opção alternativa para a escolha das } \\
\text { soluções por critérios estéticos. }\end{array}$ \\
\hline \multirow{4}{*}{$\begin{array}{l}\text { Avaliação e } \\
\text { classificação } \\
\text { do } \\
\text { desempenho } \\
\text { energético }\end{array}$} & $\begin{array}{l}\text { 1. Avaliar os dados de saída da simulação por meio de gráficos e tabelas a fim de } \\
\text { verificar se estão pertinentes. }\end{array}$ \\
\hline & $\begin{array}{l}\text { 2. Rever os dados de entrada do projeto caso tenham resultados muito acima ou abaixo } \\
\text { do esperado, pois pode representar erros de modelagem. }\end{array}$ \\
\hline & $\begin{array}{l}\text { 3. Utilizar normas (nacionais ou internacionais) para a inserção de dados para a } \\
\text { simulação no edifício. }\end{array}$ \\
\hline & 4. Classificar o nível de desempenho conforme as orientações estabelecidas por norma. \\
\hline
\end{tabular}

Figura 2 - Definição esquemática da proposta do método de projeto baseado no desempenho

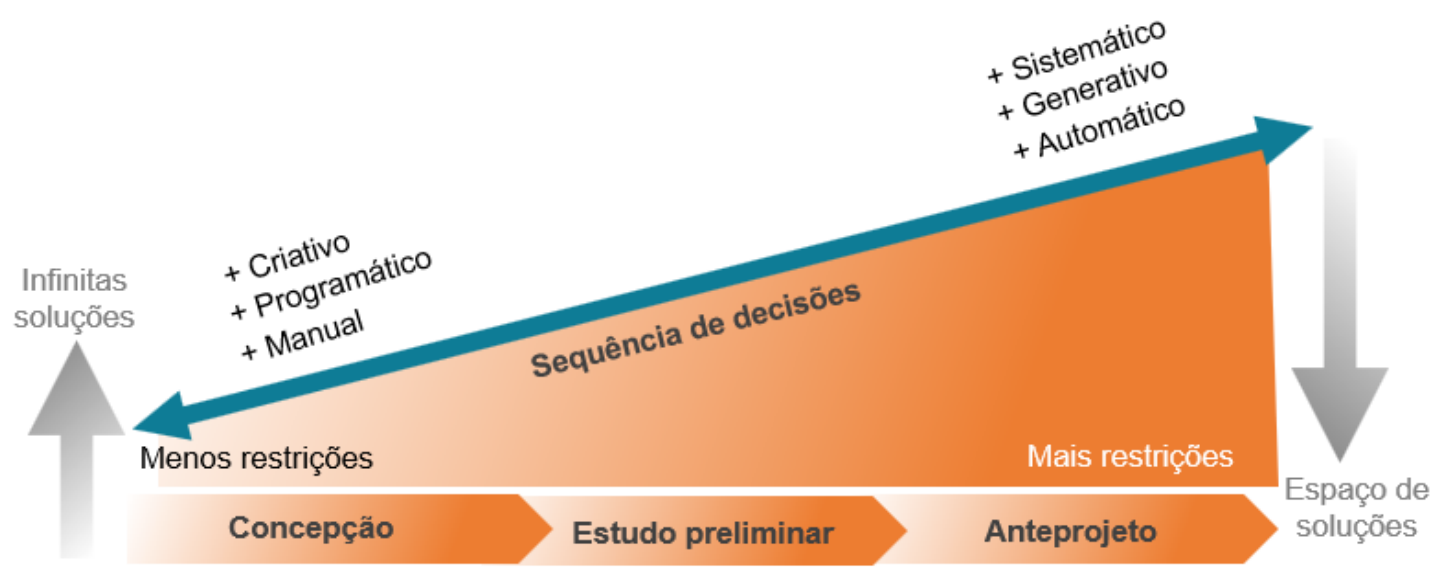

\section{Proposição do método de projeto baseado em desempenho}

Para a proposição do método, foram estruturados experimentos a partir de estudos de caso de modelos computacionais de edifícios de escritório, baseados nos parâmetros da INI-C (BRASIL, 2018), utilizando-se como referência o contexto físico e ambiental da cidade de Vitória, ES, que se localiza em uma região litorânea de clima tropical quente (ALVARES et al., 2013). É importante ressaltar que o intuito dos procedimentos experimentais não foi criar um projeto, mas sim propor um que pudesse assimilar as características reais de edifícios com essa tipologia e aplicar as restrições impostas pelo Plano Diretor Urbano (PDU), Código de Obras (CO) e as particularidades climáticas como forma de simular possíveis 
situações da prática profissional. Para tanto, foi elaborado um levantamento baseado em um recorte temporal e territorial no referido município, confrontando com os dados obtidos nas pesquisas de Maioli et al. (2018). Os critérios para o levantamento foram definidos pelas regiões com predominância da tipologia de edifícios de escritório e por ser de construção recente, executada nos últimos 15 anos. Os dados foram obtidos a partir do censo imobiliário do Sindicato da Construção Civil do Espírito Santo (SINDICATO..., 2018) associado a uma prospecção realizada pelo Google Street View. A amostragem com 6 edificações permitiu identificar características predominantes entre elas por meio de uma pesquisa direta com as construtoras locais, de modo a estabelecer a criação de um modelo do padrão construtivo, denominado como edifício genérico, conforme constata a Figura 3.

\section{Figura 3 - Caracterização do edifício genérico}

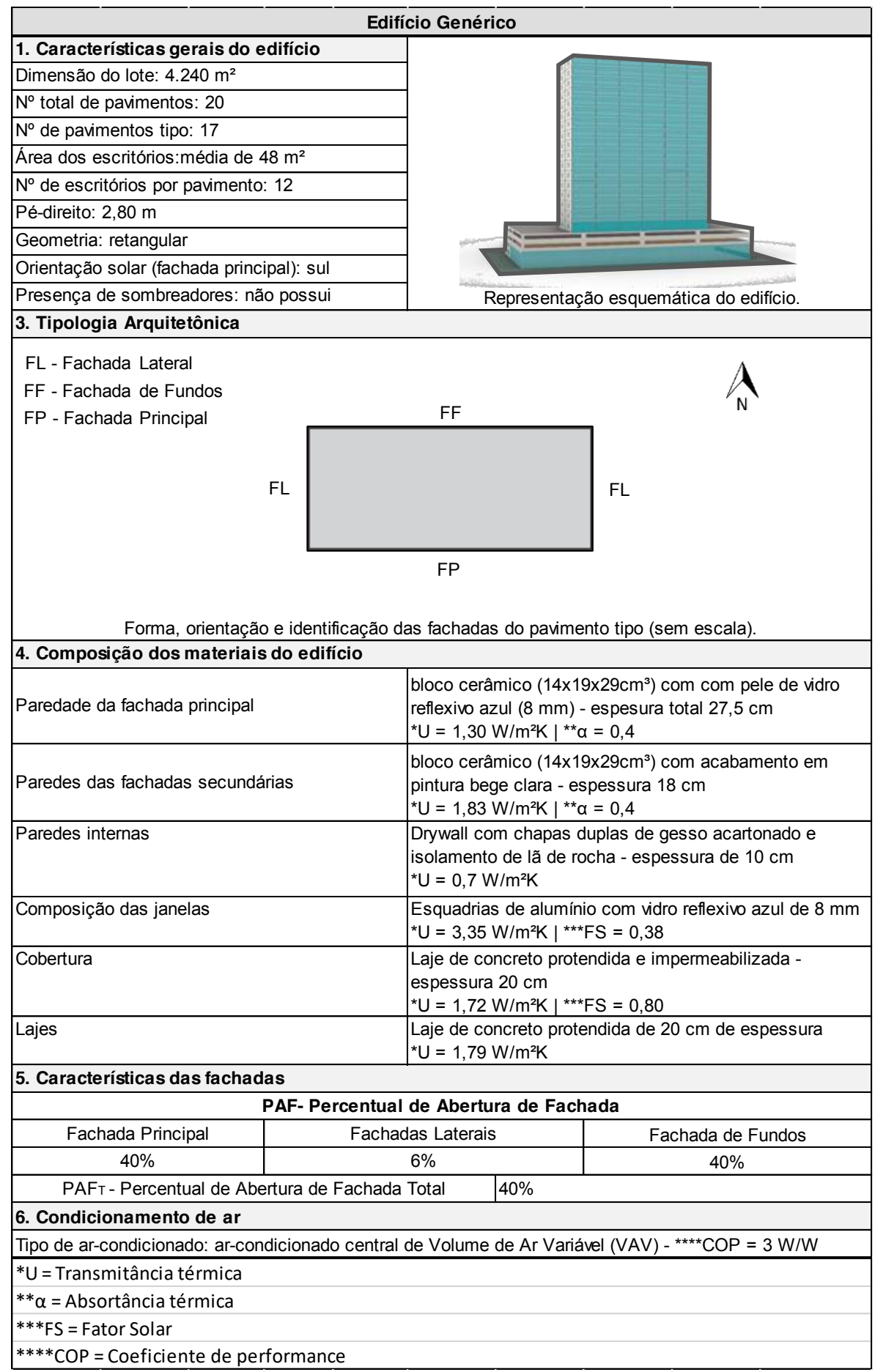


O cálculo do sistema construtivo dos materiais utilizados foi elaborado segundo os requisitos e propriedades térmicas indicadas na NBR 15220 (ABNT, 2003). Para o sistema de ar condicionado, foram empregadas informações padrão do banco de dados do software OpenStudio, por se tratar de um sistema de água gelada e com grande quantidade de configurações a serem inseridas. Vale ressaltar ainda que o programa supracitado possui como motor de simulação o EnergyPlus e interface com o Honeybee, plugin de simulação de desempenho energético do Ladybug Tools (LADYBUG..., 2019), utilizado nesta pesquisa. Sua interação com o Grasshopper, editor de algoritmos do Rhinoceros 3D, permitu - em paralelo - o desenvolvimento e a configuração da modelagem paramétrica do projeto por meio de códigos em Visual Programming Language $^{4}$ (VPL). A interoperabilidade e a capacidade no agrupamento de ferramentas tornaram o programa o mais utilizado na elaboração de projetos baseados no desempenho e na aplicação de técnicas de otimização na fase inicial de projeto (ANDRADE, 2012; KHEIRI, 2018). Devido às peculiaridades salientadas, o conjunto de ferramentas proporcionou, dentro de uma única interface gráfica, a geração, representação, simulação e otimização dos edifícios.

\section{Geração e representação}

A atividade de criação da forma e estruturação do edifício genérico partiu tanto da tipologia retangular como das características arquitetônicas predominantes no levantamento. Enfatiza-se que a geração e a representação do projeto foram elaboradas unicamente no Grasshopper. Assim sendo, a modelagem seguiu em duas fases:

(a) definições de projeto; e

(b) modelagem energética.

$\mathrm{Na}$ primeira, tendo em vista a elaboração do sistema generativo de projeto, foram criadas expressões matemáticas associadas a relações geométricas respeitando principalmente o PDU, CO e a configuração do programa de necessidades. A Figura 4 ilustra a abstração do processo de modelagem em VPL.

Na segunda fase, foram inseridos o arquivo climático da cidade de Vitória, ES, bem como dados de input da simulação fornecidos pela INI-C (BRASIL, 2018) e normas como a NBR 16401-3 (ABNT, 2008) e NBR 5413 (ABNT, 1992). Foram ajustadas também as informações referentes aos elementos arquitetônicos inseridos na otimização. As configurações estabelecidas tiveram como função, juntamente com a ferramenta de otimização, fechar o ciclo a fim de obter o loop para a automatização da geração de soluções de projeto (Figura 5).

Outro aspecto fundamental se relaciona à simplificação do modelo para a redução do tempo de simulação. Desse modo, assim como indicam o documento de referência do Energy Plus (UNITED..., 2018) e pesquisas específicas, como a elaborada por Picco, Lollini e Marengo (2014), é uma prática comum reduzir o número de pavimentos quando eles possuem ambientes com configurações semelhantes. Nesses casos, são selecionados para as análises os pavimentos da extremidade e um intermediário, sendo que os demais têm suas cargas multiplicadas, conforme destaca a Figura 6.

Esse procedimento é recomendável nos casos em que os edifícios são climatizados artificialmente, como é o caso neste artigo, ao contrário de edificações ventiladas naturalmente em que o coeficiente de pressão dos ventos pode impactar em uma variação de consumo de energia entre os pavimentos.

\section{Otimização, desempenho e avaliação}

Para a elaboração dos procedimentos metodológicos de otimização, utilizou-se como base as três etapas fundamentais enfatizadas por Nguyen, Reiter e Rigo (2014), as quais compreendem:

(a) pré-processamento;

(b) execução da otimização; e

(c) pós-processamento.

${ }^{4}$ Linguagem de programação visual. Em geral são compostas por blocos de funções baseados e correlacionados em recursos visuais. 
Figura 4 - Esquema do código do sistema generativo de projeto: (a) visão geral do código em VPL; (b) visão ampliada do código de programação em VPL referente às definições de projeto; (c) esquema simplificado do código de programação

(a)
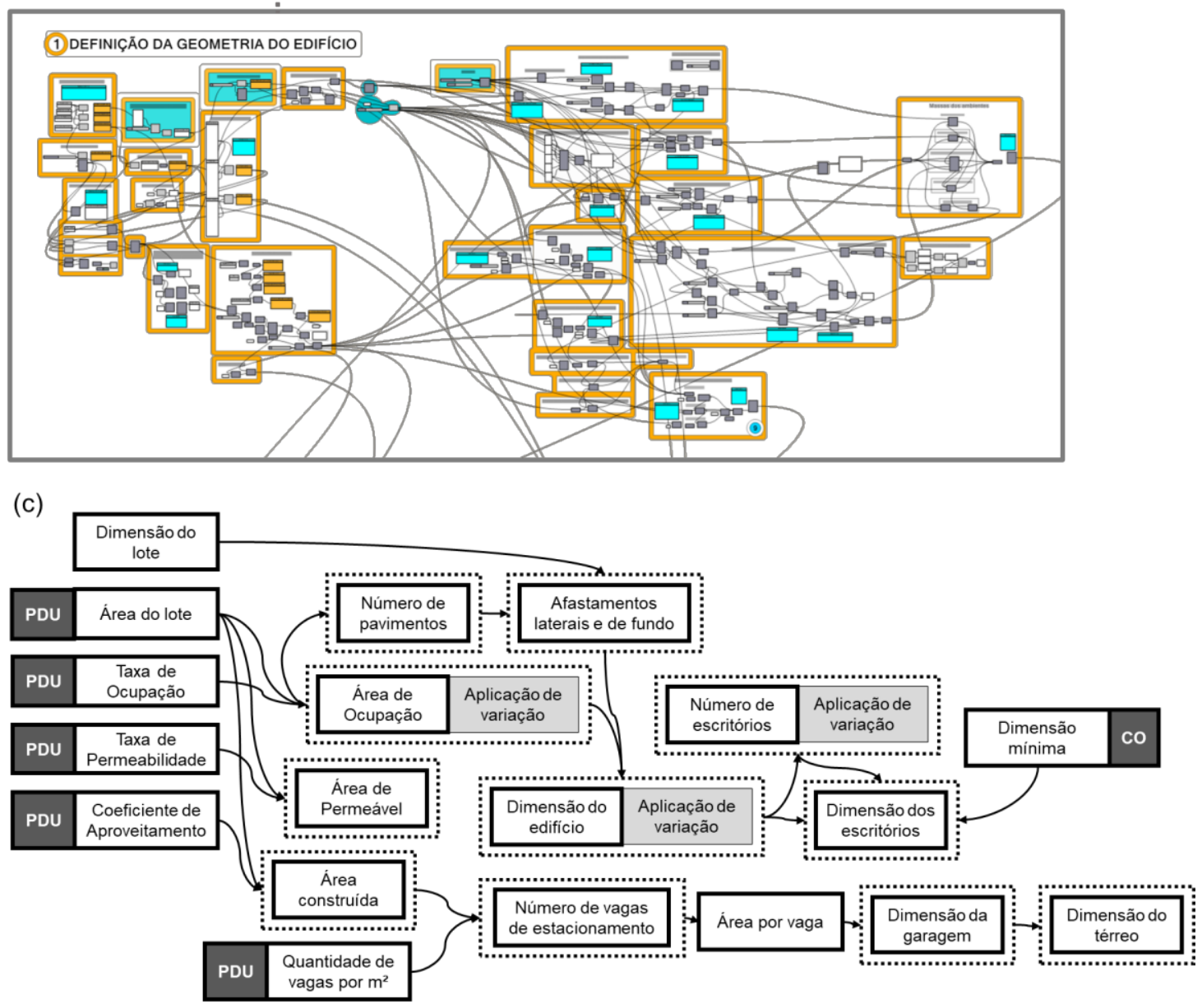

Legenda:

\begin{tabular}{l|l} 
Parâmetro relacionado \\
ao Plano Diretor Urban
\end{tabular} 
Figura 5 - Esquema do código do sistema generativo de projeto referente à modelagem energética: (a) visão geral do código em VPL; (b) visão ampliada do código de programação em VPL referente às definições de projeto; (c) esquema simplificado do código de programação referente à modelagem energética

(a)

(b)
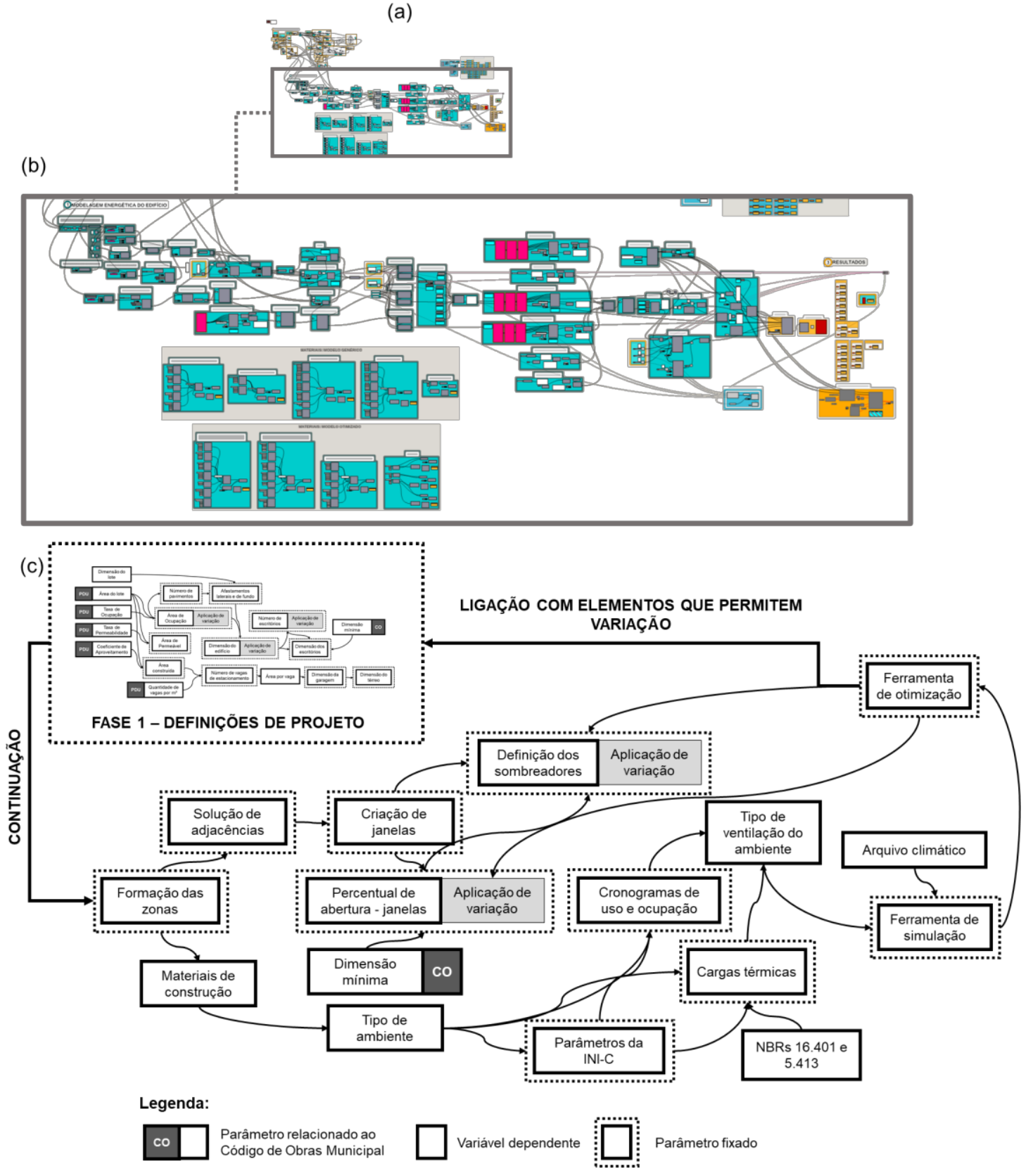


\section{Figura 6 - Simplificação da modelagem e setorização dos ambientes}

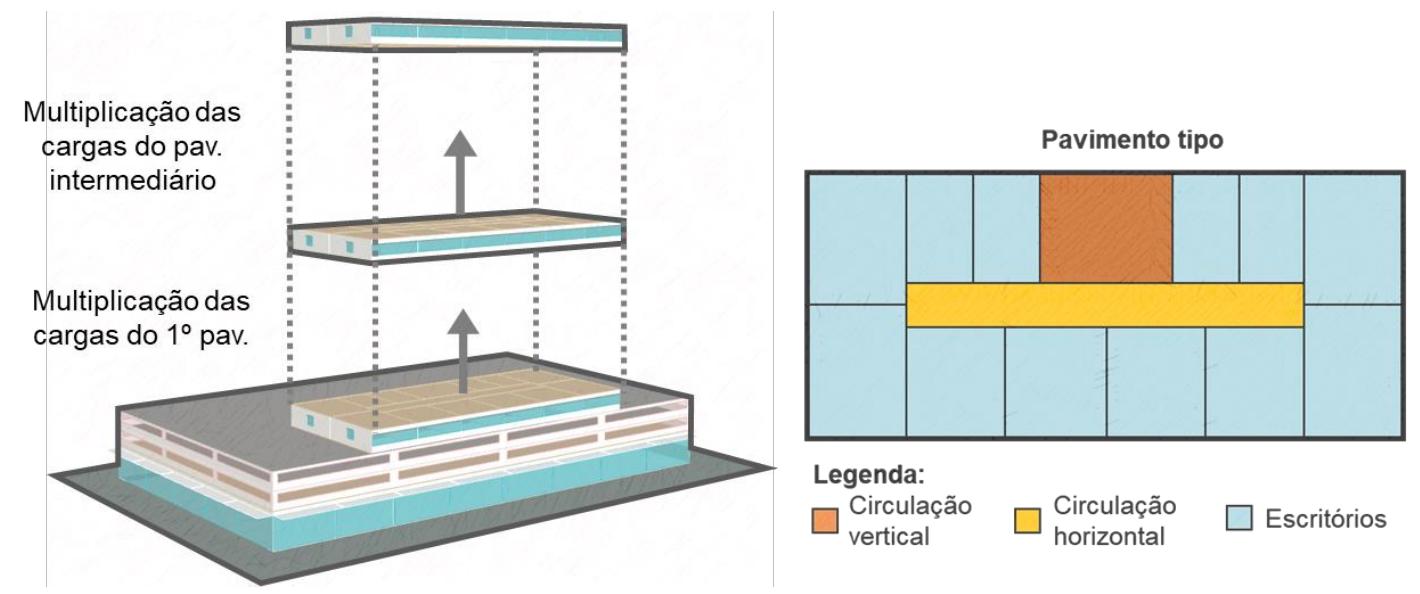

De acordo com Tian et al. (2018), mais da metade dos estudos referentes à otimização de edifícios utilizam essa configuração como estrutura lógica de organização dos processos. Desse modo, o primeiro passo do pré-processamento foi caracterizar o objetivo do problema de otimização, ou seja, para esta pesquisa, maximizar a eficiência energética do edifício genérico. Para esse fim, foi utilizada uma abordagem de objetivo único que oferece suporte para a classificação do nível de eficiência energética da edificação segundo os critérios delimitados pela INI-C (BRASIL, 2018). Tanto as funções como seus respectivos parâmetros são descritos na Equação 1 .

$\mathrm{CEP}=(($ CIL + CCAe + CEQ $) \cdot$ fcE $)+($ CCAtt. fcT $)$

Eq. 1

Onde:

CEP - consumo de energia primária

CIL - consumo do sistema de iluminação (kWh/ano);

$\mathrm{CCAe}$ - consumo do sistema de energia elétrica do sistema de condicionamento de ar ( $\mathrm{kWh} / \mathrm{ano})$;

CEQ - consumo de equipamentos/tomadas ( $\mathrm{kWh} / \mathrm{ano})$;

CCAtt - consumo de energia térmica do sistema de condicionamento de ar (kWh/ano);

fcE - fator de conversão de energia elétrica $(1,6)$; e

fcT - fator de conversão de energia térmica $(1,1)$.

Ainda na primeira fase, incrementou-se no mesmo sistema generativo do edifício genérico as modificações de elementos arquitetônicos definidos como variáveis para a implementação do processo de otimização. Esse, por sua vez, foi composto em duas etapas:

(a) otimização restrita, a qual propôs alterações pontuais na configuração da edificação como materiais de vedação, tipo de vidro, percentual de abertura total da fachada (PAFt) e composição dos elementos sombreadores; e

(b) otimização abrangente, que buscou modificações estruturais como a alteração da área, largura e quantidades de salas do pavimento tipo com os resultados obtidos na primeira etapa.

Destaca-se, porém, que os índices urbanísticos, como a taxa de ocupação, mantiveram-se constantes durante os testes. Desse modo, foi possível observar os fatores com maior impacto na eficiência energética.

Assim sendo, para os fins de avaliação e classificação do desempenho energético dos edifícios, seguiu-se a caracterização sugerida pela metodologia da INI-C (BRASIL, 2018), a qual divide os projetos em duas condições:

(a) real; e

(b) de referência. 
A primeira se caracteriza como um projeto proposto com todas as características necessárias para a avaliação; já a segunda é similar - mesma forma, número de pavimentos e orientação solar -, obedecendo às características recomendadas pela instrução normativa.

Como a ênfase do método se refere ao estágio inicial de projeto, um dos critérios principais de definição das variáveis para a otimização foi dado pela sua objetividade em favor do número e do tempo de execução das simulações. Dessa forma, as variáveis foram assumidas como discretas e contínuas de natureza mutuamente dependente, classificando a otimização como multidimensional, dinâmica e de programação linear mista. A agregação desses fatores reduziu o campo de soluções dos experimentos e permitiu a obtenção de dados de forma eficiente e consistente.

A estruturação do planejamento dos experimentos está ilustrada na Figura 7 e a compilação das informações foi inserida na Tabela $1 \mathrm{com}$ as variáveis independentes e na Tabela $2 \mathrm{com}$ as dependentes. A variável de resposta foi expressa em consumo de energia primária (CEP) com unidade em $\mathrm{kWh} /$ ano. Vale frisar que apesar de não terem sido aplicadas variações, o sistema de ar condicionado central foi modificado do sistema de VAV (presente no edifício de referência com $\mathrm{COP}=2,6 \mathrm{~W} / \mathrm{W}$ e no edifício genérico com $\mathrm{COP}=3 \mathrm{~W} / \mathrm{W}$ ) para o fluxo de refrigerante variável (VRF) com coeficiente de performance de 5,67 W/W e capacidade de resfriamento de 50,40 kWh, baseando-se em informações em modelos presentes no mercado brasileiro.

Figura 7 - Estruturação do planejamento de experimentos
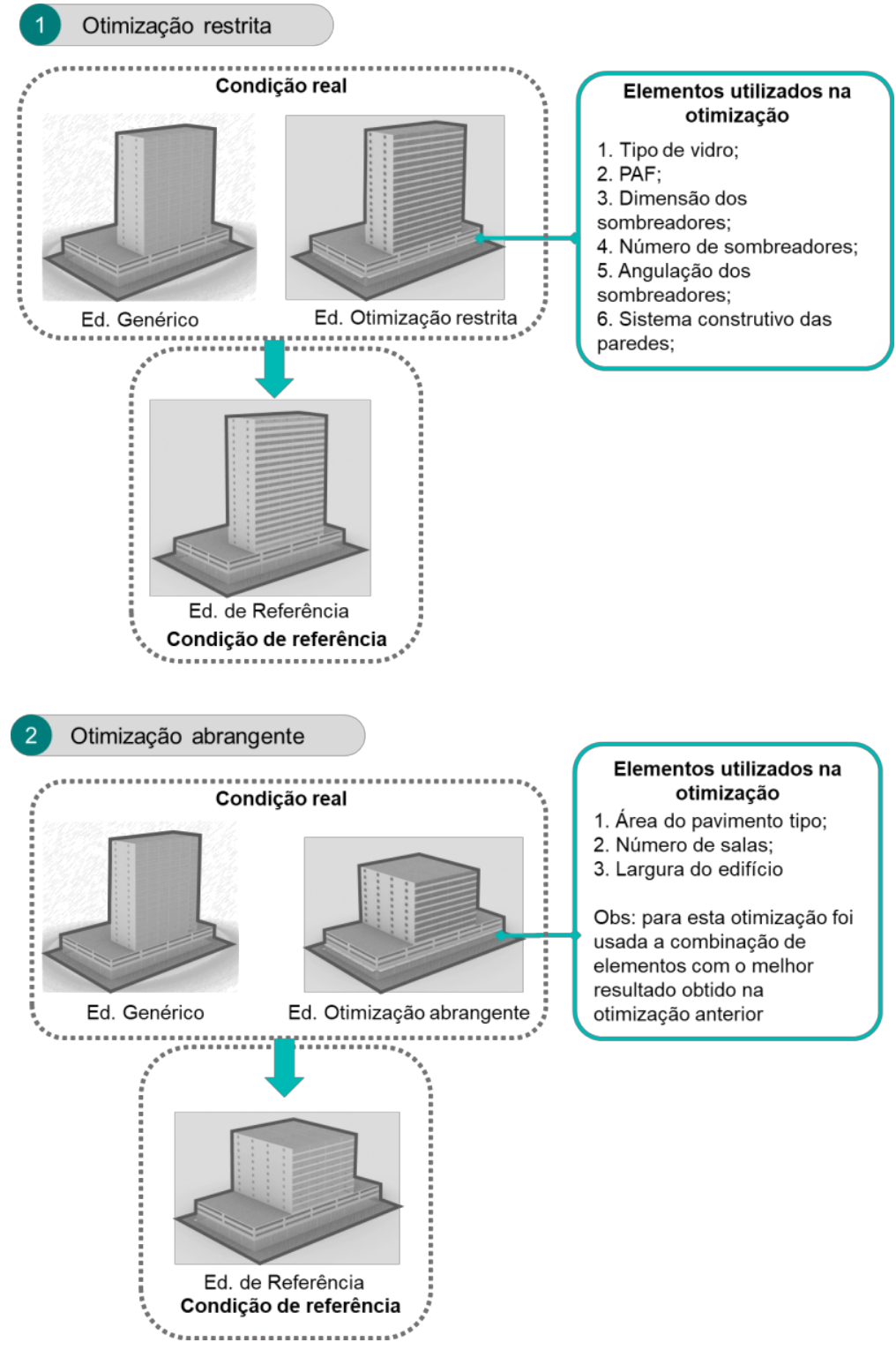
Tabela 1 - Variáveis dependentes nos experimentos

\begin{tabular}{l|c|l|c}
\hline \multicolumn{1}{c|}{ Nome da variável } & $\mathbf{N}^{\mathbf{0}}$ de níveis & \multicolumn{1}{|c}{ Níveis de variação } & Unidade \\
\hline Tipo de vidro & 4 & $3,35^{\mathrm{A}} / 1,47^{\mathrm{B}} / 1,15^{\mathrm{C}} / 0,67^{\mathrm{D}}$ & $\mathrm{W} /(\mathrm{m} / \mathrm{K})$ \\
\hline $\mathrm{PAF}_{\mathrm{T}}$ & 11 & $\begin{array}{l}30 / 35 / 40 / 45 / 50 / 55 / 60 / 65 / 70 / \\
75 / 80\end{array}$ & $\%$ \\
\hline Dimensão dos sombreadores & 4 & $0,10 / 0,20 / 0,30 / 0,40$ & $\mathrm{M}$ \\
\hline Número de sombreadores & 6 & $1 / 2 / 3 / 4 / 5 / 6$ & - \\
\hline Angulação dos sombreadores & 4 & $0 / 10 / 20 / 30$ & $\mathrm{O}$ \\
\hline Sistema construtivo das paredes & 4 & $2,75^{\mathrm{E}} / 1,84^{\mathrm{F}} / 0,34^{\mathrm{G}} / 0,38^{\mathrm{H}}$ & $\mathrm{m} / \mathrm{K})$ \\
\hline Área do pavimento tipo & 6 & $1272 / 848 / 795 / 748 / 706 / 670$ & $\mathrm{M}$ \\
\hline Largura do edifício & 6 & $35 / 36 / 37 / 38 / 39 / 40$ & - \\
\hline Número de salas & 5 & $6 / 9 / 12 / 13 / 14$ & \\
\hline
\end{tabular}

\section{Nota: Legenda:}

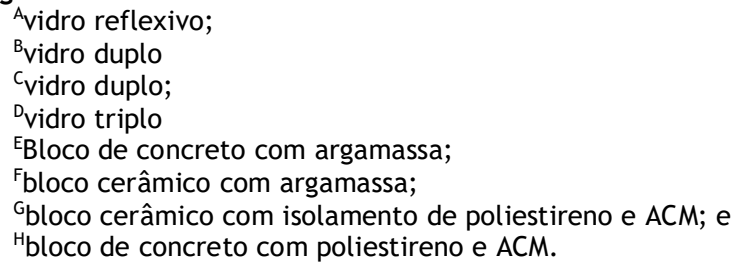

Tabela 2 - Parâmetros fixados nos experimentos

\begin{tabular}{l|c|c|l}
\hline \multicolumn{1}{c|}{ Parâmetro } & Valor & Unidade & \multicolumn{1}{c}{ Fonte } \\
\hline Pé-direito & 2,8 & $\mathrm{~m}$ & Levantamento \\
\hline Densidade de equipamentos & 9,7 & $\mathrm{~W} / \mathrm{m}$ & INI-C (BRASIL, 2018) \\
\hline Densidade de pessoas & 10 & $\mathrm{pessoas} / \mathrm{m}$ & INI-C (BRASIL, 2018) \\
\hline Ventilação por área & 0,0004 & $\mathrm{~m} / \mathrm{s} / \mathrm{m}$ & NBR 16401-3 (ABNT, 2008) \\
\hline Ventilação por pessoa & 0,0031 & $\mathrm{~L} / \mathrm{s} / \mathrm{pessoa}$ & NBR 16401-3 (ABNT, 2008) \\
\hline Tempo de ocupação diário & 10 & $\mathrm{~h}$ & INI-C (BRASIL, 2018) \\
\hline Nível de atividade & 120 & - & Biblioteca do OpenStudio \\
\hline $\begin{array}{l}\text { Tempo de uso do ar-condicionado } \\
\text { por dia }\end{array}$ & 10 & $\mathrm{~h}$ & definido a partir do tempo de ocupação \\
\hline Temperatura de Setpoint & 24 & $\mathrm{o}$ & INI-C (BRASIL, 2018) \\
\hline $\begin{array}{l}\text { Tempo de uso da iluminação } \\
\text { diariamente }\end{array}$ & 10 & $\mathrm{~h}$ & definido a partir do tempo de ocupação \\
\hline Nível de iluminação & 300 & Lux & NBR 5413 (ABNT, 1992) \\
\hline Percentual de lâmpadas dimerizadas & 50 & $\%$ & Definido pelo autor \\
\hline $\begin{array}{l}\text { Cronograma de uso de } \\
\text { equipamentos }\end{array}$ & variável & - & Biblioteca do OpenStudio \\
\hline Cronograma de infiltração de ar & variável & - & Biblioteca do OpenStudio \\
\hline
\end{tabular}

$\mathrm{Na}$ segunda etapa referente à execução da otimização, utilizou-se a ferramenta Opossum, que de acordo com o Advanced Architectural Lab (2018) é o primeiro plugin baseado em modelos substitutos para o Grasshopper. Esse método é capaz de interpolar um modelo matemático a partir de dados que relacionam os parâmetros de projeto e os critérios de desempenho (WORTMANN et al., 2015). Sua estrutura possui algoritmos de objetivo único como o RBFOpt (utilizado nesta pesquisa) formulado em Phyton, com base em técnicas matemáticas de aprendizagem de máquina para otimização de caixa preta (GITHUB, 2018). Além da sua interface simples e intuitiva, resultados recentes de sua aplicação referentes ao monitoramento de convergência de algoritmos de otimização demonstraram bom comportamento para simulações de desempenho energético e de iluminação natural. Essas características permitem menor custo computacional e redução no tempo de otimização, além de resultados consistentes (WAIBEL et al., 2019; WORTMANN, et al., 2017; WORTMANN, 2018).

Para a realização dos procedimentos foi utilizado um computador com configuração de processador Intel ${ }^{\circledR}$ Core $^{\mathrm{TM}} \mathrm{i}$ 7, memória de $16 \mathrm{gb}$, HD $1 \mathrm{~Tb}$ e SSD $250 \mathrm{~Gb}$, placa de vídeo e Quadro K2020. Como critério de estagnação da otimização foi adotado um dos padrões do Opossum que se refere a 20 iterações sem adições 
de melhorias nos resultados do objetivo. Em acréscimo, as combinações de cada variável e seu respectivo CEP foram armazenados no plugin TT Toolbox - com interface para Excel - a fim de salvar e compilar os dados obtidos.

$\mathrm{Na}$ fase de pós-processamento, foram utilizadas somente as soluções com o melhor desempenho energético obtidas no procedimento de otimização, tendo suas informações exportadas para a plataforma digital de representação gráfica das iterações chamada Design Explorer, que permite a seleção de soluções por meio de critérios estéticos. Em paralelo, os edifícios em condição real foram classificados conforme a metodologia da INI-C (BRASIL, 2018) a fim de obter o seu respectivo nível de eficiência energética. Para compreender os impactos do sistema de resfriamento, ventiladores, iluminação e equipamentos no consumo de energia dos edifícios otimizados, foram elaborados gráficos no software Excel como forma de sintetizar as informações.

Por fim, foi desenvolvida uma estimativa de influência das variáveis utilizadas na otimização em relação ao CEP dos edifícios, embora haja limitações acerca das amostras, uma vez que foram realizadas poucas iterações. Portanto, utilizou-se para esse fim a técnica de modelo de regressão linear generalizado com distribuição gama, adequado ao tratamento de dados positivos assimétricos (PAULA, 2013). Além disso, para a mensuração da influência das variáveis, foram adotados os seus primeiros níveis como categoria de referência para a comparação dos resultados. Vale ressaltar que essa é uma escolha arbitrária e não traz diferença nas análises efetuadas. Todos os testes foram calculados com um intervalo de confiança de $95 \%$. Outros cálculos que auxiliaram a compor o estudo, como o desvio padrão amostral e o erro padrão, são descritos na Equação 2 e 3, respectivamente. Deve-se salientar que o software R (versão 3.4.3) foi utilizado para as análises, confecção dos gráficos e tabelas.

$S=\sqrt{\frac{\sum_{i=1}^{n}\left(X_{i}-\bar{X}\right)^{2}}{n-1}}$

Onde:

$X i$ = i-ésima observação da amostra;

$\bar{X}=$ média amostral; e

$n=$ tamanho da amostra.

ep $=\frac{s}{\sqrt{n}}$

Eq. 3

Onde:

$S=$ desvio padrão amostral; e

$n=$ tamanho da amostra.

\section{Forma de análise dos resultados}

Os resultados dos experimentos são apresentados da seguinte maneira:

(a) tempo, quantidade de modelos gerados e convergência do algoritmo utilizado para a otimização. Esses dados foram explorados a fim de verificar a eficiência e a evolução das alternativas de projeto com maior desempenho energético;

(b) plotagem das combinações das variáveis realizadas durante a otimização e representação gráfica dos edifícios com melhor desempenho energético. Essa estratégia permitiu demonstrar um meio alternativo de pós-processamento no qual a seleção pode ser feita não somente por critérios quantitativos de desempenho, mas também por critérios qualitativos relacionados à estética resultante da combinação de variáveis;

(c) avaliação e classificação do nível de desempenho energético dos edifícios em sua condição real e de referência. Além dos percentuais de melhoria de desempenho energético são demonstradas as combinações resultantes da proposta de otimização restrita e abrangente com os impactos relativos aos sistemas que compõem a edificação; e

(d) estimativa de influência das variáveis da otimização no consumo de energia primária. Com esta análise foi possível identificar os elementos com maior impacto na eficiência energética. 


\section{Resultados e discussões}

A otimização desempenhou um papel fundamental em relação à qualidade e velocidade na obtenção de soluções de projeto. No primeiro cenário, edifício de otimização restrita, obteve-se como resultado um conjunto de 62 iterações. Porém, considerando o critério de estagnação do processo, o qual admite um número de 20 iterações sem a adição de melhorias no valor do objetivo (correspondente ao CEP), é possível assegurar a realização de 82 verificações. Nesse contexto, destaca-se que, além disso, a tendência de simplificação da modelagem corroborou para que as simulações de desempenho energético consumissem, em média, 8 minutos para sua realização. Assim sendo, a primeira fase do experimento foi compilada em aproximadamente $8 \mathrm{~h} 30$.

Em relação à convergência do algoritmo RBFOpt utilizado pela ferramenta Opossum na otimização, foi notório um progresso dos resultados em três fases distintas. Na primeira há uma queda brusca no valor do CEP, com uma redução de aproximadamente $660.000 \mathrm{kWh} /$ ano em relação à primeira iteração, em apenas uma hora, conforme destaca a Figura 8. Por outro lado, na segundo fase, verifica-se uma estabilidade até a $16^{\mathrm{a}}$ iteração, quando se inicia um declínio progressivo até estagnação do processo e a obtenção do resultado. De modo geral, a otimização possibilitou uma combinação de variáveis capazes de minimizar em até $856.000 \mathrm{kWh} /$ ano, o que representa uma melhoria de $15 \%$ dentre as possíveis configurações abarcadas na otimização restrita. Em acréscimo, conclui-se também que a primeira hora de otimização equivale a $80 \%$ dos avanços atrelados à redução do consumo de energia elétrica no projeto.

Já no que diz respeito à proposta de otimização abrangente, tanto o número de iterações como o tempo dispendido no processo foram menores. Como resultado, foram desenvolvidas 26 iterações (excluindo as correspondentes ao critério de estagnação), com a duração de três horas e trinta minutos de processamento. Diferente da restrita, a otimização abrangente assumiu um caráter único de decréscimo, sem mudanças abruptas ou estabilizações momentâneas (Figura 9). Em relação à sua configuração inicial (primeira iteração), foi obtida uma melhoria de $12 \%$ no CEP, o que corresponde à economia de $615.500 \mathrm{kWh} / \mathrm{ano}$. Em contrapartida, analisando-se globalmente todas as possibilidades de otimização no conjunto de variáveis pertinente aos experimentos elaborados, e tendo em vista o pior resultado da configuração do edifício de otimização restrita e o melhor da abrangente, o percentual de melhoria passa a corresponder a $24 \%$, ou seja, uma redução de $1.354 .100 \mathrm{kWh} /$ ano.

Figura 8 - Monitoramento de convergência da proposta de otimização restrita

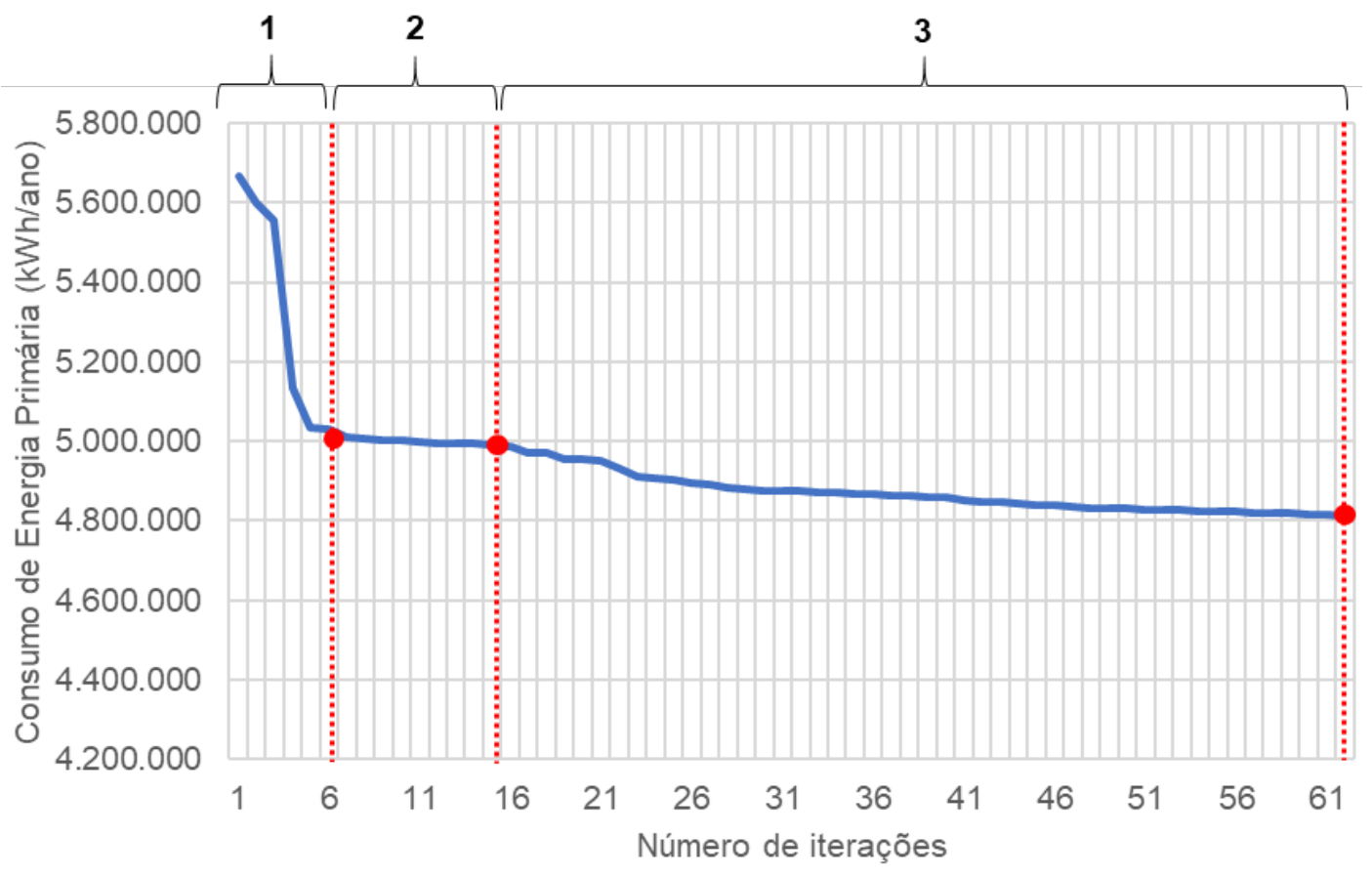

422 Costa, L. M. da; Alvarez, C. E. de; Martino, J. A. de 
Figura 9 - Monitoramento de convergência da proposta de otimização abrangente

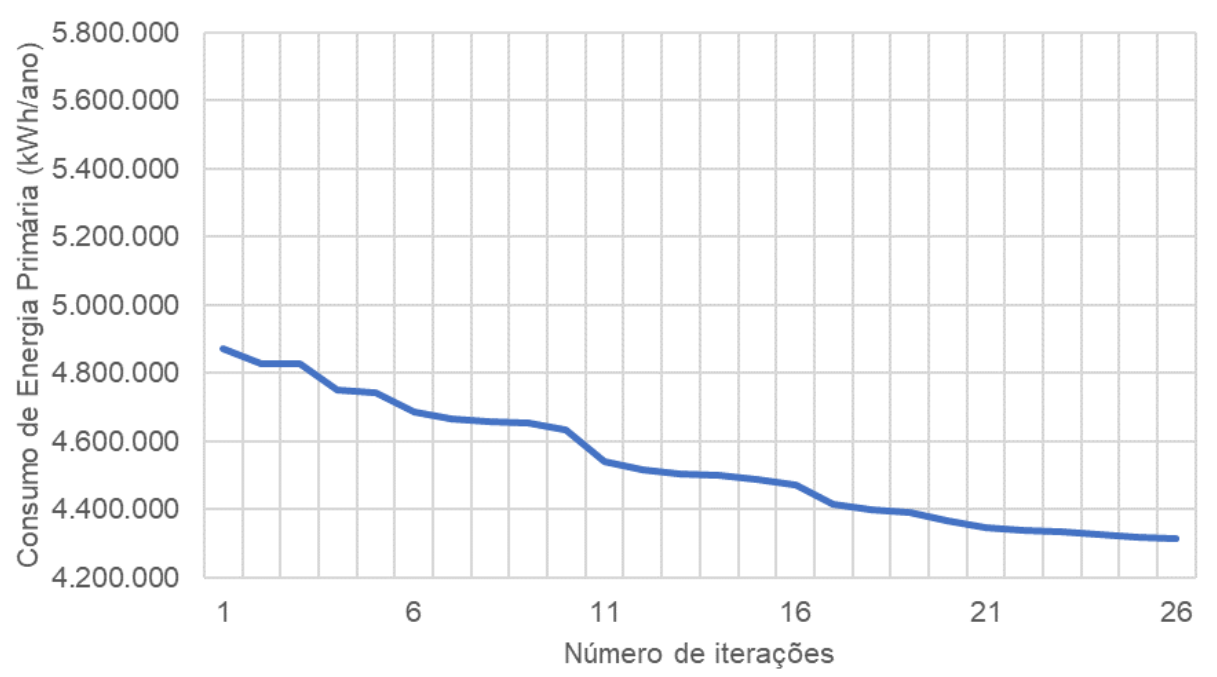

Portanto, diante do exposto, a escolha do Opossum como ferramenta de trabalho se ratificou pela pequena quantidade de iterações e uma rápida convergência do algoritmo RBFOpt, de modo a proporcionar um baixo custo computacional aliado a um curto período de otimização. Assim sendo, os testes também foram capazes de reforçar seus atributos referentes à rapidez e estabilidade para simulações de tempo intensivo durante a fase inicial de projeto, como enfatizado por Wortmann (2018). As ferramentas computacionais, portanto, demonstraram ter potencial para atender problemas de projeto com alta complexidade associados a uma curta disponibilidade de tempo.

Como um meio alternativo de pós-processamento dos dados da otimização, o Design Explorer foi capaz de associar graficamente a combinação das variáveis e seu resultado na composição estética da fachada. Essa técnica proporcionou uma abrangência não somente em aspectos quantitativos dos resultados, mas também na exploração de critérios qualitativos. As Figuras 10 e 11 apresentam os resultados obtidos para o edifício de otimização restrita e abrangente, respectivamente.

\section{Avaliação e classificação do desempenho energético}

No primeiro caso, referente à análise da condição real por meio do edifício genérico, constatou-se que, em média, as edificações pertencentes ao levantamento representam um nível intermediário de eficiência energética, classificação C, segundo o INI-C (BRASIL, 2018). No edifício de otimização restrita, a alteração e a complementação de elementos arquitetônicos no edifício possibilitaram uma melhoria de $31 \%$ na economia relativa ao CEP em comparação a sua respectiva condição de referência, e 19\% em detrimento ao edifício genérico. Já na otimização abrangente, devido a sua exploração e variação na composição da forma, foi possível um incremento de $27 \%$ na redução do consumo de energia primária em relação ao modelo genérico, e $31 \%$ no que diz respeito a sua condição de referência. Desse modo, em ambos os casos, alcançou-se classificação A, ou seja, o nível máximo de eficiência energética.

No que diz respeito às combinações das variáveis utilizadas nos experimentos, os resultados explicitados na Figura 12 evidenciam a importância tanto da escolha do sistema construtivo das paredes como da configuração do edifício em vista das condições climáticas locais da cidade de Vitória, ES. A temperatura elevada na maior parcela do ano, devido ao clima tropical úmido, necessita de elementos que auxiliem na redução da temperatura interna do edifício, como é o caso de materiais de vedação com menor transmitância térmica e dispositivos que auxiliam no sombreamento da fachada, por exemplo. Outro fator, como o aumento da área do pavimento tipo e a consequente redução do número de andares também atuou de forma positiva na redução do consumo de energia. Portanto, para analisar de forma específica o impacto dessas propostas foi necessário avaliar os sistemas que compõem a edificação. 
Figura 10 - (a) Plotagem das combinações das variáveis do edifício de otimização restrita, com destaque para o melhor desempenho; (b) representação gráfica dos pavimentos tipo simulados do edifício

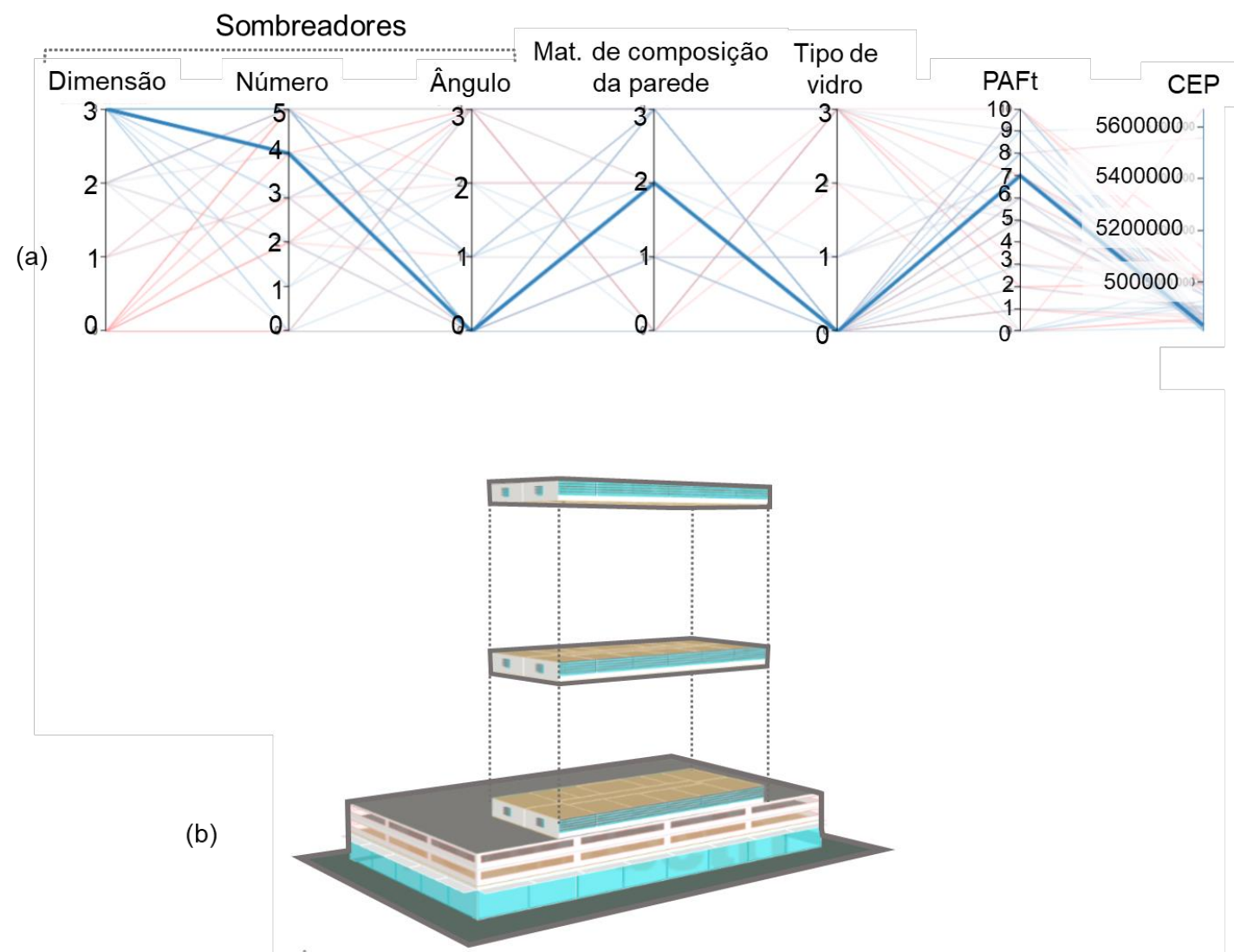

Fonte: adaptado da plataforma Design Explorer (2020).

Figura 11 - (a) Plotagem das combinações das variáveis do edifício de otimização abrangente, com destaque para o melhor desempenho; (b) representação gráfica do edifício correspondente

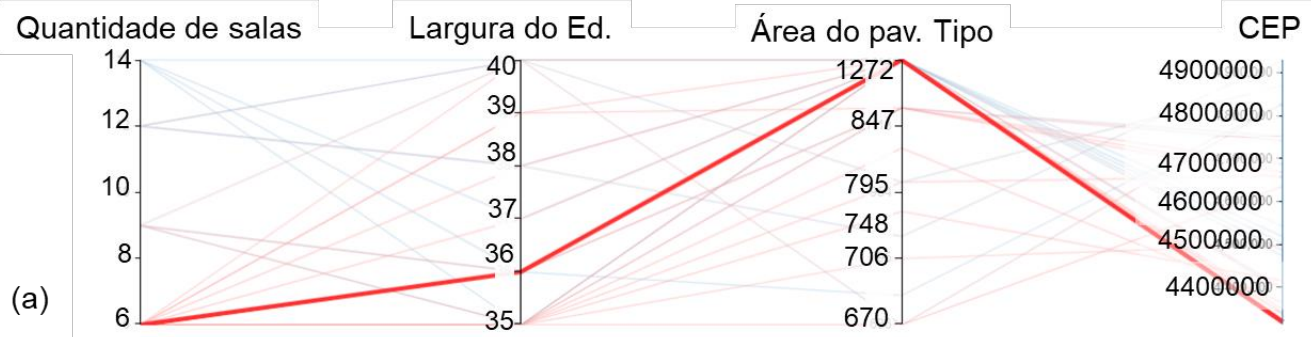

(b)

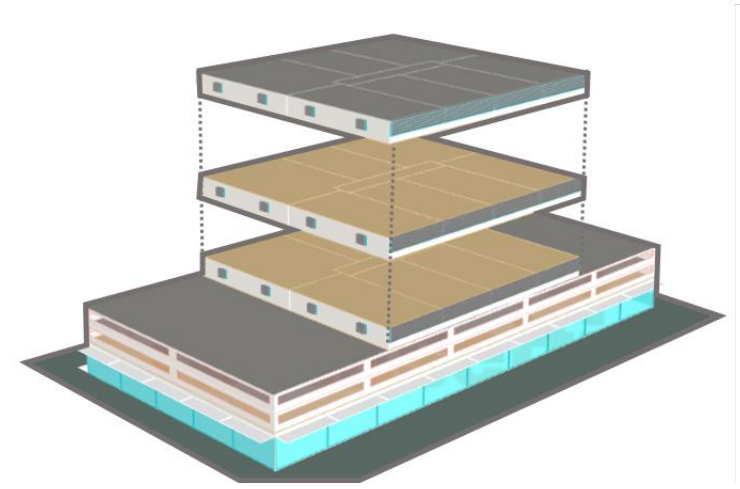

Fonte: adaptado da plataforma Design Explorer (2020). 
Figura 12 - Resultado das combinações obtidas por meio da otimização

(1) Proposta de otimização restrita

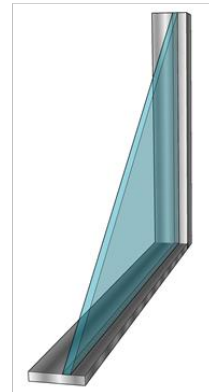

Tipo de vidro: Vidro simples

PAFT: $65 \%$

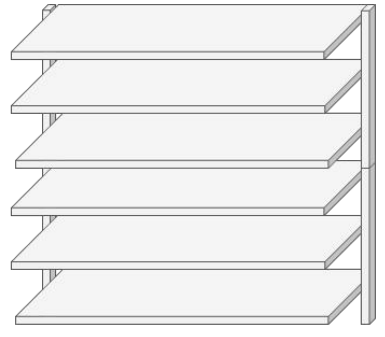

Sombreadores Dimensão: $40 \mathrm{~cm}$ Número: 6 Angulação: $0^{\circ}$

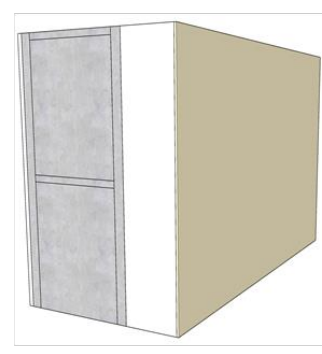

Sistema construtivo da parede: bloco de concreto com isolamento térmico

\section{Proposta de otimização abrangente}

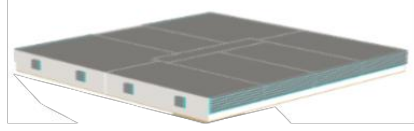

Área do pavimento tipo: $1.272 \mathrm{~m}^{2}$ Largura do edifício: $35 \mathrm{~m}$ Número de salas: 6

Na Figura 13, os resultados do consumo energético de cada sistema ao longo do ano ilustram, de forma geral, uma redução significativa da representatividade do sistema de resfriamento e o aumento no consumo dos ventiladores. Isso se deve, principalmente, pela modificação do modelo de ar condicionado central e da combinação de materiais do sistema construtivo utilizado na vedação. No edifício otimizado o VRF exerce de forma mais criteriosa o controle da temperatura conforme a exigência por resfriamento de cada ambiente, diferentemente do VAV usado na condição de referência. Sendo assim, devido à variabilidade de demanda há maior necessidade de diferenciação do fluxo de ar frio, o que exige maior precisão dos ventiladores. A Figura 14 demonstra a variação anual do percentual de economia do sistema de resfriamento com uma média de 51\%. Apesar de não sofrer alterações tão notáveis, a iluminação artificial foi capaz de gerar uma economia anual de $21 \%$. Desse modo, tanto o aumento da proporção das janelas como a utilização de dimerizadores e sombreadores corroboram de forma positiva para maior eficiência do sistema nos meses com incidência de insolação indireta e direta, respectivamente.

Por outro lado, ainda que a proposta de otimização abrangente apresente resultados semelhantes à otimização restrita, é necessário abordar algumas particularidades que a distingue. Inicialmente, a alteração da área referente à torre do edifício e a consequente diminuição no número de pavimentos ocasionou a consequente redução na superfície de incidência de radiação solar. Esse aspecto levou à economia de aproximadamente $8 \%$ do consumo relativo ao resfriamento. Em contrapartida, a subtração do número de salas no pavimento tipo e o aumento nas dimensões da largura do edifício gerou um pequeno acréscimo de $7.348 \mathrm{kWh} /$ ano no sistema de iluminação artificial. 
Figura 13 - Consumo mensal e total de energia elétrica por sistema na otimização restrita e sua respectiva condição de referência

\section{Edifício de referência}
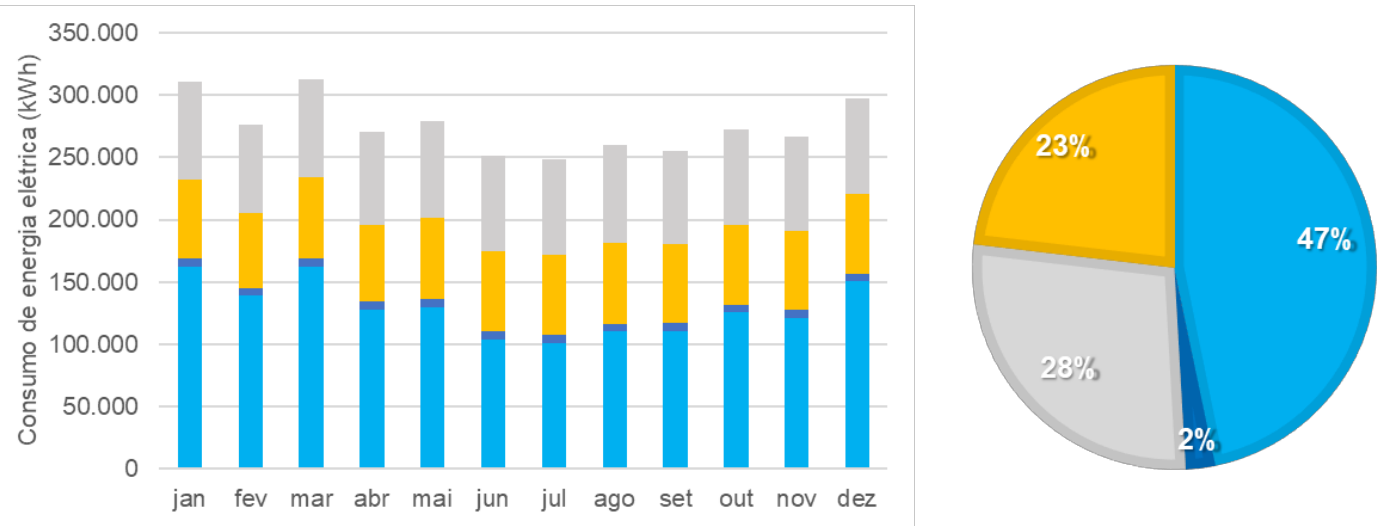

\section{Edifício referente a proposta de otimização restrita}

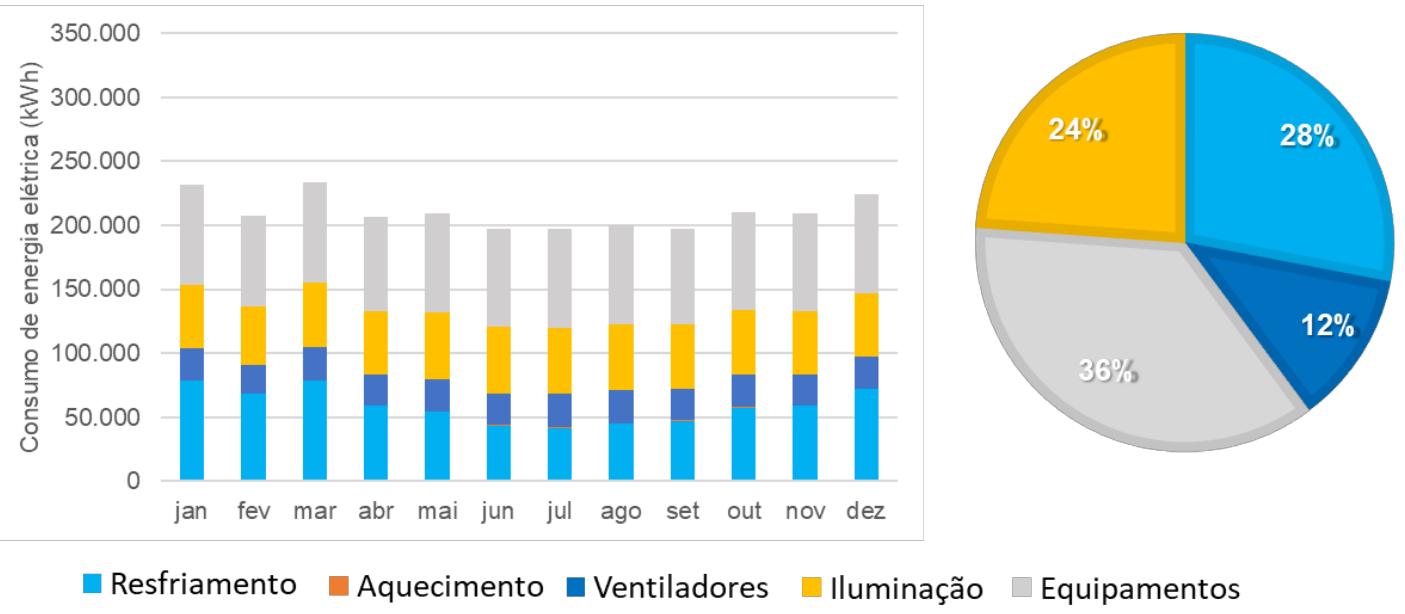

Figura 14 - Consumo de energia elétrica do sistema de resfriamento na modelagem de otimização restrita

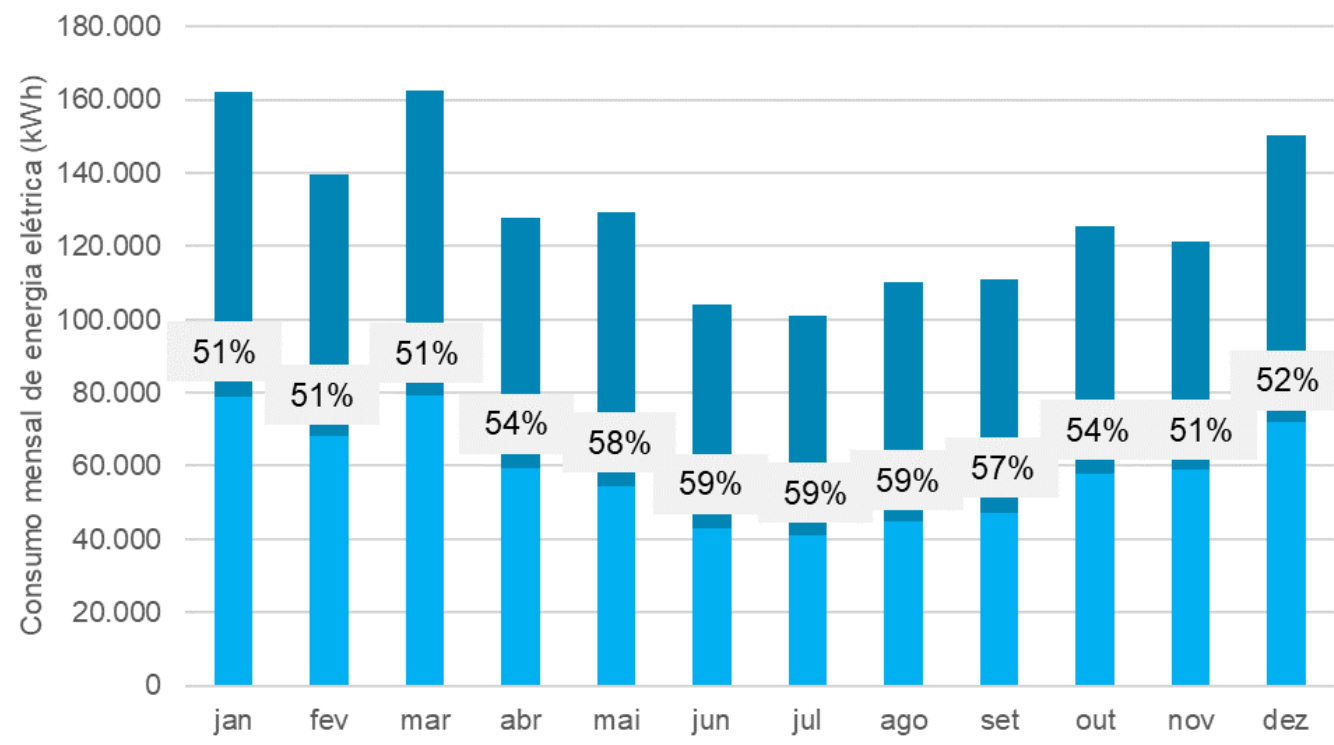

॥ Edifício referente a proposta de otimização restrita $\quad$ Edifício de referência 


\section{Influência das variáveis na eficiência energética}

Devido às particularidades da otimização, optou-se por realizar uma estimativa de influência das variáveis nos resultados relacionados ao desempenho energético. No edifício de otimização restrita, a média do CEP, assim como o desvio padrão dos parâmetros de cada variável, foram agrupadas a fim de verificar seus respectivos impactos (Figuras 15 e 16). No que diz respeito às características dos sombreadores, pode-se destacar três aspectos:

(a) a angulação maior do que $10 \%$ afeta negativamente o consumo de energia;

(b) a influência da largura do elemento sombreador passa a ser pouco significativa após os $30 \mathrm{~cm}$; e

(c) a combinação de sombreadores, em geral, permite um melhor desempenho.

Já em relação às janelas $\left(\mathrm{PAF}_{\mathrm{T}}\right.$ e tipo de vidro), há uma ampla variabilidade e incertezas associadas ao tamanho da amostra fornecida pela otimização, o que pode denotar, também, a dependência dessas variáveis quanto à combinação com outros elementos arquitetônicos para o seu bom desempenho. Por fim, a composição do sistema construtivo das paredes apresentou melhor eficiência quando integrada com materiais de isolamento térmico.

Figura 15 - Plotagem das variáveis relacionadas aos sombreadores na otimização restrita e seus efeitos no consumo de energia primária
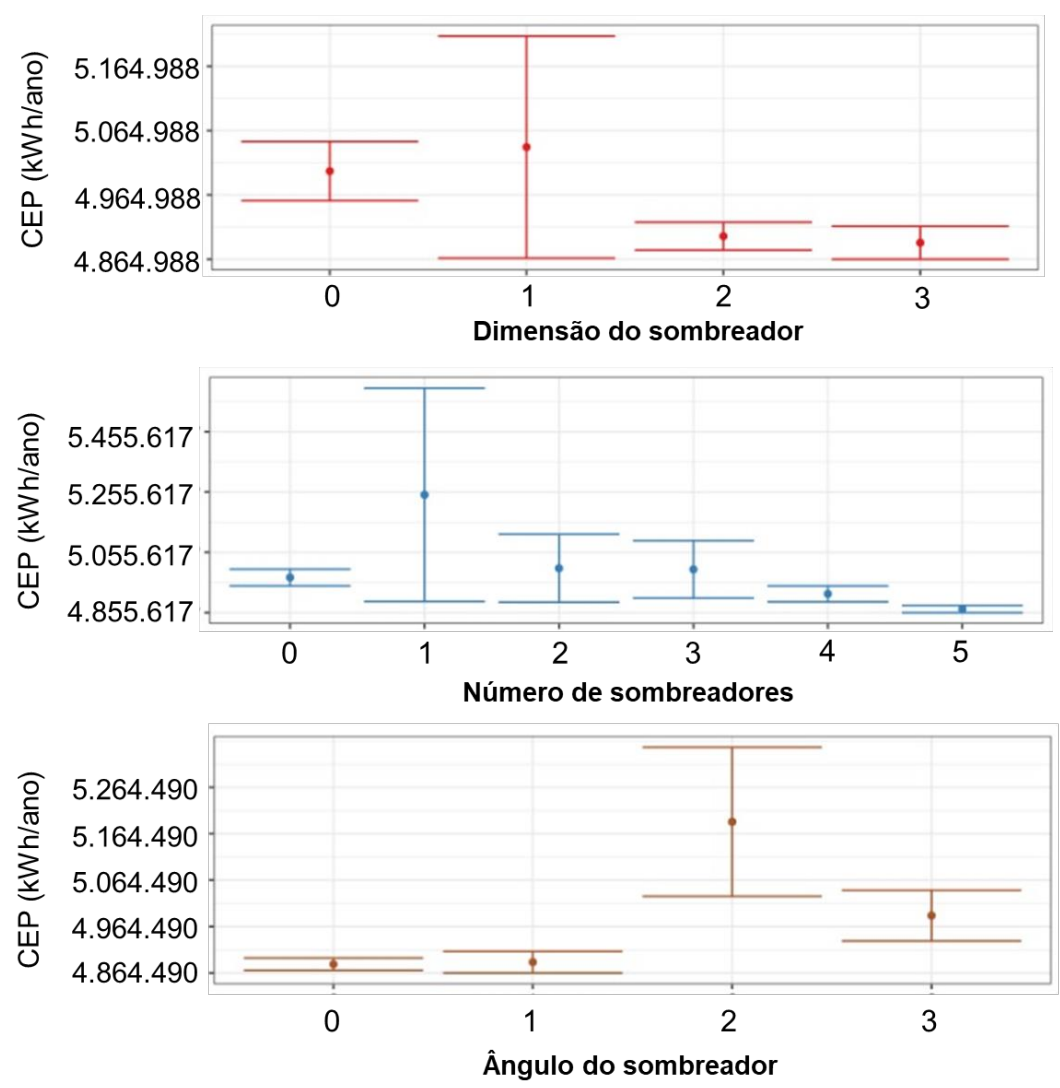

Legenda:

\begin{tabular}{|c|c|c|c|c|c|c|c|}
\hline \multirow{2}{*}{ Variável } & \multirow{2}{*}{ Unidade } & \multicolumn{7}{|c|}{ Níveis de variação } \\
\cline { 3 - 8 } & & 0 & 1 & 2 & 3 & 4 & 5 \\
\hline Dimensão & $\mathrm{cm}$ & 10 & 20 & 30 & 40 & - & - \\
\hline Número & - & 1 & 2 & 3 & 4 & 5 & 6 \\
\hline Ângulo & $\circ$ & 0 & 10 & 20 & 30 & - & - \\
\hline
\end{tabular}


Figura 16 - Plotagem das variáveis relacionadas às aberturas, materiais e vidros na otimização abrangente e seus efeitos no consumo de energia primária
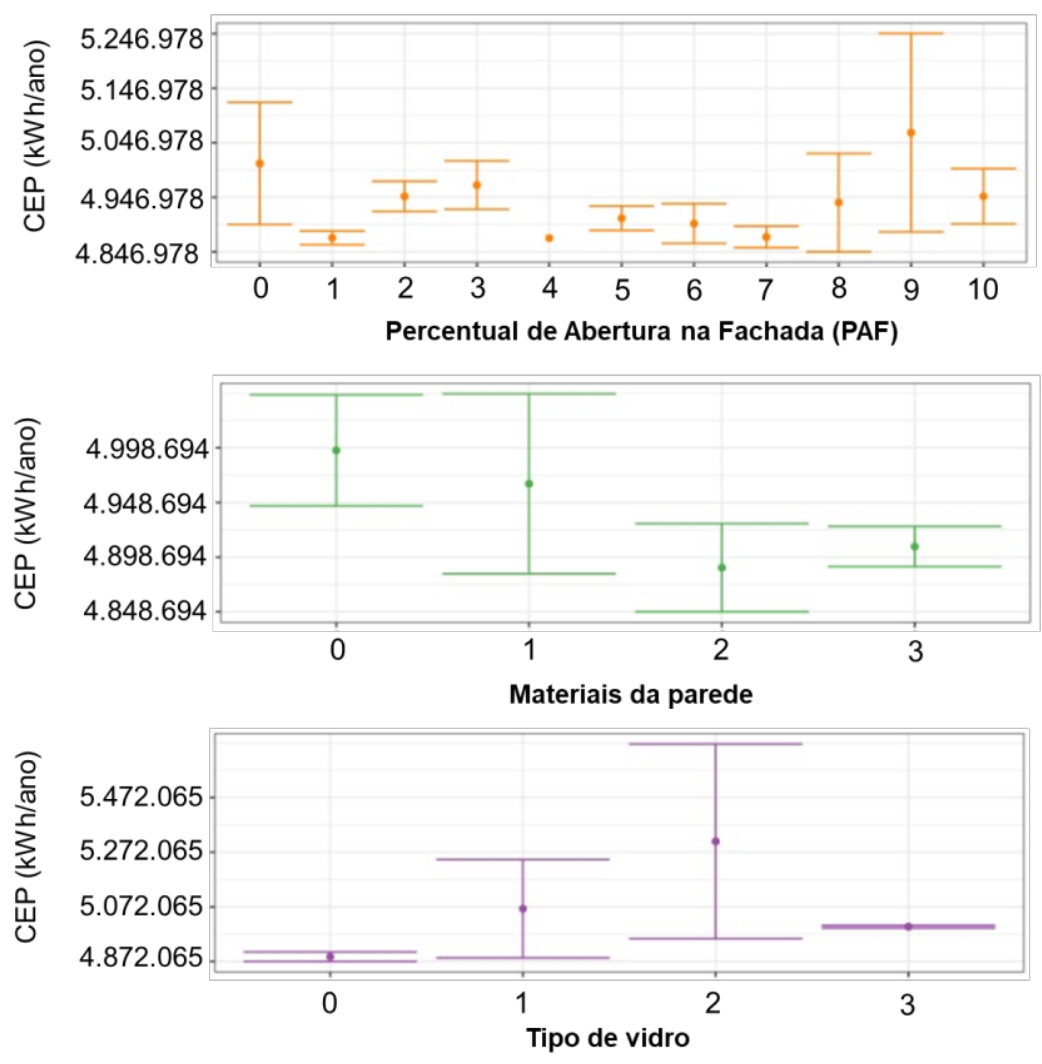

Legenda:

\begin{tabular}{|c|c|c|c|c|c|c|c|c|c|c|c|c|}
\hline \multirow{2}{*}{ Variável } & \multirow{2}{*}{ Unidade } & \multicolumn{11}{|c|}{ Níveis de variação } \\
\hline & & 0 & 1 & 2 & 3 & 4 & 5 & 6 & 7 & 8 & 9 & 10 \\
\hline PAF & $\%$ & 30 & 35 & 40 & 45 & 50 & 55 & 60 & 65 & 70 & 75 & 80 \\
\hline $\begin{array}{c}\text { Sistema } \\
\text { construtivo }\end{array}$ & $\mathrm{W} /\left(\mathrm{m}^{2} / \mathrm{K}\right)$ & $\begin{array}{c}\text { Bloco } \\
\text { cerâmico }\end{array}$ & $\begin{array}{c}\text { Bloco } \\
\text { cerâmico com } \\
\text { isolamento }\end{array}$ & $\begin{array}{l}\text { Bloco de } \\
\text { concreto }\end{array}$ & $\begin{array}{l}\text { Bloco de } \\
\text { concreto com } \\
\text { isolamento }\end{array}$ & - & - & - & - & - & - & - \\
\hline Vidro & - & $\begin{array}{c}\text { Vidro } \\
\text { simples }\end{array}$ & Vidro duplo & $\begin{array}{c}\text { Vidro } \\
\text { duplo } 2\end{array}$ & Vidro triplo & - & - & - & - & - & - & - \\
\hline
\end{tabular}

Verificou-se também a influência das variáveis na otimização restrita (Tabela 3), sendo que as que obtiveram maior significância estatística foram o tipo de vidro, o $\mathrm{PAF}_{\mathrm{T}} \mathrm{e}$ o ângulo do sombreador considerando o P-valor $\leq 0,05$ devido ao intervalo de confiança de $95 \%$. Em relação aos efeitos dos parâmetros no consumo de energia primária, pode-se destacar que as composições em que foram adotados o tipo de vidro 1 (vidro duplo) e o ângulo do sombreador de $30^{\circ}$ apresentaram aumento médio de 6,79\% e $3,66 \%$ no CEP, respectivamente. Em contrapartida, no caso do percentual de abertura da fachada, as composições proporcionaram decréscimo no consumo de energia primária em aproximadamente 4,85\% $\left(\mathrm{PAF}_{\mathrm{T}} 35 \%\right), 5,93 \%\left(\mathrm{PAF}_{\mathrm{T}} 50 \%\right)$ e 2,64\% $\left(\mathrm{PAF}_{\mathrm{T}} 55 \%\right)$.

Quanto à proposta de otimização abrangente, a presença de poucas variáveis facilitou a percepção da influência de cada parâmetro no desempenho energético do projeto. Desse modo, a partir das análises efetuadas nos resultados obtidos na distribuição gama, notou-se um impacto mais significativo quanto à área do pavimento tipo e a quantidade de salas. Sendo assim, o modelo permitiu concluir que o aumento de uma sala levou a um acréscimo médio de $0,5 \%$ no CEP, enquanto o incremento de $100 \mathrm{~m}$ de área possibilitou a redução de $1 \%$ no consumo de energia. 
Tabela 3 - Estimativa dos efeitos das variáveis de otimização restrita no CEP

\begin{tabular}{|c|c|c|c|}
\hline Variável & Valor estimado & Limite inferior & Limite superior \\
\hline Dimensão do sombreador: 1 & $1,35 \%$ & $-3,01 \%$ & $5,93 \%$ \\
\hline Dimensão do sombreador: 2 & $-1,27 \%$ & $-3,65 \%$ & $1,17 \%$ \\
\hline Dimensão do sombreador: 3 & $-1,99 \%$ & $-4,18 \%$ & $0,26 \%$ \\
\hline Número de sombreadores: 1 & $3,76 \%$ & $-1,38 \%$ & $9,20 \%$ \\
\hline Número de sombreadores: 2 & $-2,64 \%$ & $-5,82 \%$ & $0,70 \%$ \\
\hline Número de sombreadores: 3 & $0,91 \%$ & $-2,36 \%$ & $4,28 \%$ \\
\hline Número de sombreadores: 4 & $-1,17 \%$ & $-3,76 \%$ & $1,49 \%$ \\
\hline Número de sombreadores: 5 & $-1,65 \%$ & $-3,82 \%$ & $0,57 \%$ \\
\hline Ângulo do sombreador: 1 & $0,86 \%$ & $-1,33 \%$ & $3,10 \%$ \\
\hline Ângulo do sombreador: 2 & $3,66 \%$ & $0,32 \%$ & $7,11 \%$ \\
\hline Ângulo do sombreador: 3 & $0,14 \%$ & $-1,80 \%$ & $2,12 \%$ \\
\hline Sistema construtivo da parede: 1 & $-1,00 \%$ & $-3,53 \%$ & $1,61 \%$ \\
\hline Sistema construtivo da parede: 2 & $-1,78 \%$ & $-3,76 \%$ & $0,24 \%$ \\
\hline Sistema construtivo da parede: 3 & $-1,42 \%$ & $-3,38 \%$ & $0,58 \%$ \\
\hline Tipo de vidro: 1 & $1,17 \%$ & $-2,01 \%$ & $4,47 \%$ \\
\hline Tipo de vidro: 2 & $6,79 \%$ & $2,12 \%$ & $11,70 \%$ \\
\hline Tipo de vidro: 3 & $0,56 \%$ & $-1,70 \%$ & $2,86 \%$ \\
\hline $\mathrm{PAF}_{\mathrm{T}}: 1$ & $-4,85 \%$ & $-8,92 \%$ & $-0,61 \%$ \\
\hline $\mathrm{PAF}_{\mathrm{T}}: 2$ & $-2,23 \%$ & $-5,86 \%$ & $1,54 \%$ \\
\hline $\mathrm{PAF}_{\mathrm{T}}: 3$ & $-2,77 \%$ & $-6,85 \%$ & $1,49 \%$ \\
\hline $\mathrm{PAF}_{\mathrm{T}}: 4$ & $-5,93 \%$ & $-12,18 \%$ & $0,80 \%$ \\
\hline $\mathrm{PAF}_{\mathrm{T}}: 5$ & $-2,64 \%$ & $-5,80 \%$ & $0,63 \%$ \\
\hline PAF $_{\mathrm{T}}: 6$ & $-1,83 \%$ & $-5,50 \%$ & $1,99 \%$ \\
\hline $\mathrm{PAF}_{\mathrm{T}}: 7$ & $-2,62 \%$ & $-5,42 \%$ & $0,25 \%$ \\
\hline $\mathrm{PAF}_{\mathrm{T}}: 8$ & $-1,21 \%$ & $-4,43 \%$ & $2,11 \%$ \\
\hline $\mathrm{PAF}_{\mathrm{T}}: 9$ & $-0,06 \%$ & $-3,81 \%$ & $3,84 \%$ \\
\hline $\mathrm{PAF}_{\mathrm{T}}: 10$ & $-1,55 \%$ & $-4,96 \%$ & $1,97 \%$ \\
\hline
\end{tabular}

\section{Conclusão/considerações finais}

O método desenvolvido para a elaboração de projeto baseado em desempenho associou aspectos de modelagem paramétrica, técnicas de otimização, avaliação e classificação do desempenho energético, contemplando um estudo de caso para um edifício de escritórios. As ferramentas digitais de modelagem e otimização revelaram uma ampla potencialidade de exploração e flexibilização na busca de alternativas relacionadas à eficiência energética.

Dentre os resultados obtidos, destaca-se que os experimentos do estudo de caso conseguiram demonstrar a contribuição do método para a redução do consumo de energia primária na fase inicial de projeto. A implementação das modificações por meio da otimização gerou um total de 88 iterações em 12 horas de processamento somando a proposta de otimização restrita e abrangente, obtendo-se um edifício com uma melhoria de $31 \%$ na eficiência energética, ou seja, redução de $2.168 .300 \mathrm{kWh} /$ ano. Esses dados, aliados ao algoritmo de otimização RBFOpt e a sua respectiva técnica de aprendizagem de máquina, permitiram concluir que houve um rápido e significativo avanço na obtenção de soluções de edifícios com maior desempenho energético. Outro ponto importante a ressaltar é a influência das variáveis na otimização, em que se obteve maior significância estatística em relação ao $\mathrm{PAF}_{\mathrm{T}}$, ângulo do sombreador e tipo de vidro, que podem servir como base para o aprimoramento e maior detalhamento em fases posteriores de projeto.

Em relação ao método, existem dois aspectos a serem comentados:

(a) o critério de escolha, que permite direcionar a solução apenas pelo desempenho ou associá-la a critérios estéticos; e

(b) a adequação à proposta, em que o sistema generativo permite a adaptação do código de programação a outras geometrias de edifício e (ou) parâmetros conforme o objetivo pretendido.

Sendo assim, a metodologia pode se configurar a diferentes características físicas e ambientais de aglomerados urbanos brasileiros, possibilitando estudos tipológicos de melhor desempenho energético. 


\section{Referências}

ADVANCED ARCHITECTURAL LAB. Opossum. Disponível em: https://aal.sutd.edu.sg/opossum/. Acesso em: 10 nov. 2018.

ALVARES, C. A. et al. Köppen's climate classification map for Brazil. Meteorologische Zeitschrift, v. 22, n. 6, p. 711-728, 2013.

ANDRADE, M. L. V. X. O projeto baseado no desempenho na prática arquitetônica recente: estrutura conceitual. Campinas, 2012. Tese (Doutorado em Engenharia Civil) - Universidade Estadual de Campinas, Campinas, 2012.

ANDRADE, M. L. V. X.; RUSCHEL, R. G. Projeto baseado no desempenho na prática arquitetônica recente: estrutura conceitual. Arquitextos, v. 150, n. 7, 2012.

ASSOCIAÇÃO BRASILEIRA DE NORMAS TÉCNICAS. NBR 15220: desempenho térmico de edificações: parte 2: métodos de cálculo da transmitância térmica da capacidade térmica, do atraso térmico e do fator solar de elementos e componentes de edificações. Rio de Janeiro, 2003.

ASSOCIAÇÃO BRASILEIRA DE NORMAS TÉCNICAS. NBR 16401-3: instalações de ar-condicionado, sistemas centrais e unitários: parte 3: qualidade do ar interior. Rio de Janeiro, 2008.

ASSOCIAÇÃO BRASILEIRA DE NORMAS TÉCNICAS. NBR 5413: iluminância de interiores. São Paulo, 1992.

BRASIL. Decreto no 4.059, de 19 de dezembro de 2001. Regulamenta a Lei no 10.295, de 17 de outubro de 2001, que dispõe sobre a Política Nacional de Conservação e Uso Racional de Energia, e dá outras providências. Brasília, 2001. Disponível em: http://www.planalto.gov.br/ccivil_03/decreto/2001/D4059.htm. Acesso em: 12 fev. 2020.

BRASIL. Portaria no 248, de 10 de julho de 2018. Aperfeiçoamento do Regulamento técnico da Qualidade para a Classe de Eficiência Energética de Edifícios Comerciais, de Serviços e Públicos, 2018. Disponível em: http://www.inmetro.gov.br/legislacao/rtac/pdf/RTAC002520.pdf. Acesso em: 12 fev. 2020.

DESIGN EXPLORER. Building Performance Study - Demo. Disponível em: https://ttacm.github.io/DesignExplorer/. Acesso em: 10 jan. 2020.

EKICI, B. et al. Performative computational architecture using swarm and evolutionary optimisation: a review. Building and Environment, v. 147, p. 356-371, 2019.

EVINS, R. A review of computational optimisation methods applied to sustainable building design. Renewable and Sustainable Energy Reviews, v. 22, p. 230-245, jun. 2013.

FONSECA, L. P. G. et al. Otimização multiobjetivo das dimensões dos ambientes de uma residência unifamiliar baseada em simulação energética e estrutural. Ambiente Construído, Porto Alegre, v. 17, n. 1, p. 267-288, jan./mar. 2017.

GITHUB. RBFOpt. Disponível em: https://github.com/coin-or/rbfopt. Acesso em: 10 nov. 2018.

INSTITUTO NACIONAL DE METROLOGIA, NORMALIZAÇÃO E QUALIDADE INDUSTRIAL.

Portaria no 372, de 17 de setembro de 2010. Com alterações das portarias: nº 17 de 2012 e no 299 de 2013. Regulamento Técnico da Qualidade do Nível de Eficiência Energética de Edifícios Comerciais, de Serviços e Públicos (RTQ-C). Brasília, 2013. Disponível em:

http://www.pbeedifica.com.br/sites/default/files/projetos/etiquetagem/comercial/downloads/Port372-

2010_RTQ_Def_Edificacoes-C_rev01.pdf. Acesso em: 18 jan. 2020.

INTERNATIONAL ENERGY AGENCY. Annual Energy Outlook 2019 with Proj. to 2050. Annual.. 2020. Disponível em: https:/www.eia.gov/outlooks/aeo/pdf/aeo2019.pdf. Acesso em: 20 jan. 2020.

INTERNATIONAL ENERGY AGENCY. Energy Efficiency 2019. Rio de Janeiro, 2019.

JABI, W. Parametric design for architecture. London: Laurence King Publishing, 2013.

KALAY, Y. E. Performance-based design. Automation in Construction, v. 8, n. 4, p. 395-409, 1999.

KHEIRI, F. A review on optimization methods applied in energy-efficient building geometry and envelope design. Renewable and Sustainable Energy Reviews, v. 94, p. 897-920, 2018. 
KOLAREVIC, B. Back to the future: performative architecture. International Journal of Architectural Computing, v. 2, n. 1, p. 43-50, 2005.

KONIS, K.; GAMAS, A.; KENSEK, K. Passive performance and building form: an optimization framework for early-stage design support. Solar Energy, v. 125, p. 161-179, 2016.

KOWALTOWSKI, D. C. C. K. et al. Reflexão sobre metodologias de projeto arquitetônico. Ambiente Construído, Porto Alegre, v. 6, n. 2, p. 7-19, abr./jun. 2006.

LADYBUG TOOLS. Ladybug tools. Disponível em: https://www.ladybug.tools/. Acesso em: 10 nov. 2019.

MACHAIRAS, V.; TSANGRASSOULIS, A.; AXARLI, K. Algorithms for optimization of building design: a review. Renewable and Sustainable Energy Reviews, v. 31, p. 101-112, 2014.

MAIOLI, R. N. et al. A transformação da fachada na tipologia construtiva de edifícios comerciais verticais em Vitória - ES e sua relação com o conforto ambiental. In: ABDALA, M. R. W. S. (org.).

Complementaridade: Arquitetura, Engenharia e Construção. Ponta Grossa: Atena Editora, 2018.

MINISTÉRIO DE MINAS E ENERGIA. EMPRESA DE PESQUISA ENERGÉTICA. Balanço energético nacional 2019. Rio de Janeiro, 2019.

MONIZZA, P. G.; BENDETTI, C.; MATT, D. T. Parametric and Generative Design techniques in massproduction environments as effective enablers of Industry 4.0 approaches in the Building Industry.

Automation in Construction, v. 92, p. 270-285, 2018.

NEGENDAHL, K. Building performance simulation in the early design stage: An introduction to integrated dynamic models. Automation in Construction, v. 54, p. 39-53, 2015.

NGUYEN, A.; REITER, S.; RIGO, P. A review on simulation-based optimization methods applied to building performance analysis. Applied Energy, v. 113, p. 1043-1058, 2014.

ØSTERGÅRD, T.; JENSEN, R. L.; MAAGAARD, S. E. Building simulations supporting decision making in early design: a review. Renewable and Sustainable Energy Reviews, v. 61, p. 187-201, 2016.

OXMAN, R. Digital architecture as a challenge for design pedagogy: theory, knowledge, models and medium. Design Studies, v. 29, n. 2, p. 99-120, 2008.

OXMAN, R. Performative design: a performance-based model of digital architectural design. Environment and Planning B: Planning and Design, v. 36, n. 6, p. 1026-1037, 2009.

OXMAN, R. Theory and design in the first digital age. Design Studies, v. 27, n. 3, p. 229-265, 2006.

PAULA, G. A. Modelos de regressão com apoio computacional. São Paulo: EDUSP, 2013.

PICCO, M.; LOLLINI, R.; MARENGO, M. Towards energy performance evaluation in early stage building design: A simplification methodology for commercial building models. Energy and Buildings, v. 76, p. 497-505, 2014.

SINDICATO DA CONSTRUÇÃO CIVIL DO ESPÍRITO SANTO. Pesquisa. Disponível em: http://www.sinduscon-es.com.br/v2/cgi-bin/pesquisa.asp. Acesso em: 10 nov. 2018.

TERZIDIS, K. Algorithmic Architecture. Oxford: Elsevier, 2006.

TIAN, Z. et al. Towards adoption of building energy simulation and optimization for passive building design: A survey and a review. Energy and Buildings, v. 158, p. 1306-1316, 2018.

UNITED STATES DEPARTAMENT OF ENERGY. Tips and tricks for using EnergyPlus. Washington: U.S Departament of Energy, 2018..

WAIBEL, C. et al. Building energy optimization: an extensive benchmark of global search algorithms. Energy and Buildings, v. 187, p. 218-240, 2019.

WONG, L. I.; KRÜGER, E. Comparing energy efficiency labelling systems in the EU and Brazil: implications, challenges, barriers and opportunities. Energy Policy, v. 109, p. 310-323, 2017.

WOODBURY, R. Elements of parametric design. New York: Routledge, 2010.

WORTMANN, T. Efficient, visual and interactive architectural design optimization with model-based methods. Singapore, 2018. Thesis (Doctor of Philosophy) - Singapore University of Technology and Design, Singapore, 2018. 
WORTMANN, T. et al. Advantages of surrogate models for architectural design optimization. AI EDAM, v. 29, n. 4, p. 471-481, 2015.

WORTMANN, T. et al. Model-based optimization for architectural design: optimizing daylight and glare in Grasshopper. TechnologylArchitecture + Design, v. 1, n. 2, p. 176-185, 2017.

\section{Agradecimentos}

Os autores agradecem à CAPES e à FAPES pelo suporte e financiamento da pesquisa.

\section{Lucas Martinez da Costa}

Departamento de Arquitetura e Urbanismo | Universidade Federal do Espírito Santo | Av. Fernando Ferrari, 514, Goiabeiras, CEMUNI I, sala 7 | Vitória - ES - Brasil | CEP 29075-910 | Tel.: (27) 4009-2581 | E-mail: lucasmartinezlmc@gmail.com

\section{Cristina Engel de Alvarez}

Departamento de Arquitetura e Urbanismo | Universidade Federal do Espírito Santo | E-mail: cristina.engel@ufes.br

\section{Jarryer Andrade de Martino}

Departamento de Arquitetura e Urbanismo | Universidade Federal do Espírito Santo | Av. Fernando Ferrari, 514, Goiabeiras, CEMUNI III | Vitória - ES - Brasil | CEP 29075-910 | Tel.: (27) 4009-2565 | E-mail: jarryer.martino@ufes.br

\section{Ambiente Construído}

Revista da Associação Nacional de Tecnologia do Ambiente Construído Av. Osvaldo Aranha, $99-3^{\circ}$ andar, Centro

Porto Alegre - RS - Brasil

$$
\text { CEP } 90035-190
$$

Telefone: +55 (51) 3308-4084

Fax: +55 (51) 3308-4054

www.seer.ufrgs.br/ambienteconstruido

E-mail: ambienteconstruido@ufrgs.br 